\title{
Parameter interdependence and success of skeletal muscle modelling
}

\author{
Peter A. Huijing a,b, * \\ ${ }^{a}$ Instituut voor Fundamentele en Klinische Bewegingswetenschappen, Faculteit Bewegingswetenschappen, \\ Vrije Universiteit, Van der Boechorststraat 9, 1081 BT Amsterdam, The Netherlands \\ ${ }^{b}$ Biomedisch Technologisch Instituut, Vakgroep Biomedische Werktuigbouwkunde, Universiteit Twente, \\ Enschede, The Netherlands
}

\begin{abstract}
In muscle and movement modelling it is almost invariably assumed that force actually exerted is determined by several independent factors. This review considers the fact that length force characteristics are not a relatively fixed property of muscle but should be considered the product of a substantial number of interacting factors. Level of activation and recruitment are influential factors in relation to aspects of muscle architecture. For the level of activation effects of its short term history (potentiation, fatigue in sustained contractions) have to be taken into account and are reviewed on the basis of recent experimental results as well as available literature. History is also an important determinant for the effect of length changes. This concept is introduced on the basis of recent experimental evidence as well as available literature. Regarding effects of muscle architecture, the concepts of primary and secondary distribution of fibre mean sarcomere length are introduced as well as effects of muscle geometry for mono- and bi-articular muscles on those distributions. Implications for motor control are discussed and the need for intramuscular coordination indicated.
\end{abstract}

\section{Introduction}

Much scientific effort has been devoted towards modelling of skeletal muscle and of movement. This effort started in the 17 th century (e.g.,

\footnotetext{
${ }^{*}$ Corresponding author.
} 
Stensen, 1667; Borelli, 1680) and is continued in the present at an enormous volume due to the development of easily accessible computational facilities.

In order to create a systematic approach to these phenomena, first a short description of the goals, principles and strategies will be provided below as an introduction. Subsequently, a number of muscle characteristics will be reviewed specifically.

The major purposes of this presentation is (1) to consider systematically a number of muscular properties, (2) to discuss effects of inclusion or neglecting such properties in muscle modelling and to evaluate the need to consider such properties in muscle and movement modelling, and (3) to describc somc cffects of such properties for the control and coordination of movement.

\subsection{Modelling goals}

In general muscle modelling is done with the following major goals:

1. To study mechanism within and characteristics of single muscles. Two major substreams can be distinguished:

1.1. The study of more or less isolated fundamental principles or mechanisms of muscle activity (e.g., Hill, 1938; Huijing and Woittiez, 1984; van Ingen Schenau et al., 1988; Bobbert et al., 1990; Ettema and Huijing, 1990; Hatze, 1990).

1.2. To study more integrated characteristics of muscle, its excitation (e.g., Hill, 1970; Huxley, 1957; Hatze, 1981; Zahalak and Ma, 1990; Zahalak, 1990; Ma and Zahalak, 1991).

2. To incorporate muscle models in models of the body(-segments) to simulate human (e.g., Hatze, 1976; Hatze, 1977; Pedotti et al., 1978; Dul et al., 1984; Bobbert et al., 1986a; Bobbert et al., 1986b; Zajac, 1989; Thunnisse, 1993; Franken, 1993) or animal movement (van Leeuwen, 1992) and study its control. The distinguished categories 1 and 2 are similar to Winters' muscle physiologists and system bioscientists' approaches (Winters, 1995).

\subsection{Modelling strategies}

In modelling strategy two important features can be distinguished namely the principal approach and the direction of analysis. 


\section{Principal approach}

Building models always involves simplification of reality. These simplifications will generally be made according to the principle approaches indicated below:

- by using the system analysis approach by including some mathematical description of input output characteristics of a neuromuscular entity, a muscle or its parts, without regard for the actual mechanism involved in creating the particular characteristics (descriptive models, e.g., Baratta and Solomonow, 1992).

- by incorporating the most important physical and/or physiological principles, which explain the causes of certain muscle characteristics (explanatory models).

Explanatory models can be based on either structural considerations (structural models, e.g., Sliding filament theory of contraction (Huxley, 1957), Distribution Moment model (Zahalak, 1990)) or can be based on considerations of principles not involving actual structural entities ( phenomenological models, e.g., Hill type models (e.g., Hill, 1950)). The vast majority of present day muscle and movement models is based on this type of model involving in its simplest form a contractile element and a series elastic element. Its impact on understanding of muscle function cannot easily be overrated. In several cases the need for anatomically identifiable parameters has led some modellers to equate the series elastic element to the tendinous tissues of the tendon and aponeurosis by neglecting intracellular series elastic components or ascribing total series elastic component values to these structures (e.g., Bobbert et al., 1990).

Muscle modelling will always involve a combination of the description and explanation strategies, because even in explanatory models, a choice has to be made at what level explanation will start. The enlargement of the descriptive level is always an effective way of enhancing the simplicity of the model.

\section{Direction of analysis}

Several directions of analysis are found in muscle modelling:

- Direct mechanical analysis. The direction of analysis is in general terms from the inside to the outside of the body, i.e., the model is used to relate properties of parts of the analyzed system to that of the whole system, taking into account the mechanics of interaction of the subsystem. Examples are the modelling of muscle characteristics on the basis 
of fibre and aponeurosis characteristics and the modelling of movement of the body (parts) on the basis of muscle and joint characteristics,

- Inverse mechanical analysis. On the basis of variables which are accessible for external measurement (e.g., reaction forces, etc.) models are used to calculate joint moments and forces. On the basis of joint moments muscle forces may be calculated.In engineering this type of application is very recognizable in the design process of machines. Successful strength analyses and design of for example protheses (e.g., Lemmers, 1994) are based on mechanical modelling as well as the application of considerable safety margins.

- Combined direction mechanical analysis. A combination of these two approaches is also found in models which use inverse mechanics of human movement to calculate forces and moments around a particular joint in combination with direct mechanical modelling of muscles to study the production of the required net moments and forces (e.g., Thunnisse, 1993).

\section{Types of application}

As the aims of the modelling work are so important for the strategy of modelling, further consideration should take into account the type of application intended. Two types of uses can be distinguished:

(1) Heuristic application, i.e., the model is applied to quantitatively study effects of potentially important mechanisms of muscle function. In this type of application it is not the exactness of the prediction which is most important but the possibility to manipulate the mechanisms of choice so that in effect "experiments of thought" can be performed to test or generate idea's. This particularly useful in cases in which the behaviour of the muscle is too complicated to review without modelling. Comparison with data obtained through empirical research is necessary to check if the mechanisms modelled are actually active in a real muscle and if no other major features are over-looked. These empirical experiments should not be confused with sensitivity analysis of models to its selected parameters. In that sense it may be unwise to refer to running the model as an experiment. Because of the nature of the goals of this type of model application most progress is often made if the model results do not agree well with experimental results. In such cases there is certainty that the model and thus the idea's on which the models are build should be revised or extended. In the case of a much better correspondence of model and experimental results there is always the possibility that the agreement is 
coincidental because of interactions or cancelling of opposing effects Despite the fact that the main purpose of modelling in this type of application is the generation of idea's, combination of this type of application of models, with experimentation is crucial because the process of empirical confrontation of the model with reality will prevent the use of models which have little to do with reality.

(2) Predictive application, i.e., the model is used to predict the behaviour of the muscle within a certain allowable range of error. Even though acceptance of a certain range of error is absolutely necessary as the model will always be a simplification of reality, in predictive applications a major goal is always a prediction with as high a correspondence as possible to what actually happens within the muscle. In many cases this approach is used to obtain information on variables that can not be measured directly (Zajac and Winters, 1990). This is of course accompanied by the inherent risk that the model predictions can not be validated directly by experimentation! Sometimes this type of application is aimed at determining the requirements of strategies of artificial control of muscle (e.g., Baratta and Solomonow, 1992) or predicting effects of compensation for the pathology by the healthy parts of the locomotor apparatus (e.g. Winter et al., 1990). Particularly, in clinical settings one expects such applications of muscle modelling, because there, the aims are not in the first place to generate new idea's about the functioning and control of the muscle, but to use the model for diagnosis and to pinpoint pathological deviation from the normal as well as the location or level of the abnormality.

\section{Complexity of the model}

The question arises how simple or complex models of either type or application should be. This question has received some attention in the literature (e.g., Audu and Davy, 1985; Winters and Stark, 1987; Baratta and Solomonow, 1992) From a practical point of view any model of muscle or locomotor apparatus should be as simple as possible in the light of the aims for which it is made. This view would arise already from exclusively considering the efficiency considerations of the modelling work itself (e.g., Audu and Davy, 1985). However, two much more important factors will be the limited control over very complicated muscles and the difficulty of obtaining appropriate parameters for the model. If a model is so complex that the reason for certain phenomena can not be intuitively located once the effects have been described, a sizable danger is that the modeller looses the connection with important biological elements that he is trying to 
model. In such a case if the model does not describe reality reasonably well very little may be learned from that fact.

Particularly in modelling in vivo muscles or movement of humans, the difficulty obtaining appropriate parameter values is very apparent. Because of this difficulty, particularly authors involved in this type of work may select parameters from the literature on the basis of the availability rather than the appropriateness. It can be concluded that in modelling work not always an enhanced sense of responsibility is shown for the parameters used in the models. Combination of modelling work and experimental work could alleviate this problem. However, labs equipped for this type of modelling work are not always suitable for experimentation aimed at obtaining for example muscle parameters. This problem should be solved through increased interdisciplinary cooperation. Such cooperation will also have as a consequences that myology labs will become more interested in performing experiments as asked for by modellers (see also Winters, 1995). However modellers should also be willing to invest time and interest in performing such experiments in interdisciplinary cooperation as they bear responsibility for parameters used in models.

The factor of appropriate parameter values will be more important in predictive than in heuristic applications. For the above described reasons parameter choice based solely on specific experimental measurements rather than on values from the literature should be commended (e.g., Durfee and Palmer, 1994), but it is clear that such purity of approach will not always be possible.

It is obvious that uncertainty of each of the parameters will affect the uncertainty of the model results. On top of that, increasing the number of parameters will also increase the chance of interference of errors leading to possible agreement of model and experimental results in specific conditions of movement without agreement in underlying mechanisms of model and muscular reality. The clearly present and very human bias of researchers, journal referee's and funding agencies in the direction of positive results of research projects will only lead to increased incidence of models which, despite the fact that a reasonable agreement with empirical results may be presented, may have little to do with the reality of human movement.

Physiological features generally incorporated in muscle models

Almost invariably features incorporated in muscle models with either heuristic or predictive goals are: 
I. length force characteristics, and II. force velocity characteristics:

Often muscle are modelled under conditions of maximal activation (Hill, 1938; Huijing and Woittiez, 1984; Huijing and Woittiez, 1985; Bobbert et al., 1986a; Bobbert et al., 1986b; Otten, 1988; Lieber et al., 1992; Bobbert and van Zantwijk, 1994), but characteristics of muscles under conditions of submaximal activation are also modelled by varying.

III. degree of activation:

- by simple grading of force (e.g., Zajac, 1989; Winters and Stark, 1987; Winters and Woo, 1990; Thunnisse, 1993)

- through recruitement (e.g., Coggshall and Bekey, 1970; Hawkins and Hull, 1992; Heckman and Binder, 1993b)

- or firing rate coding (e.g., Heckman and Binder, 1993a)

Only very occasionally time dependent characteristics of muscle are included in the model:

IV. fatiguability characteristics:

(e.g. Hawkins and Hull, 1993). These authors compartementilized muscle in a fatiguable and a non-fatiguable section. The effects of fatigue were modelled by grading of force.

Almost always the fundamental characteristics of muscle or muscle-tendom complex ( $I$ through $I V$ in the paragraph above) are modelled as being independent (e.g., Woittiez et al., 1984; Bobbert et al., 1986a, Bobbert et al., 1986b; Zajac, 1989; Hawkins and Hull, 1992; Hawkins and Hull, 1993; Thunnisse, 1993). If this would be correct a high degree of simplification can be attained by modelling these characteristics in descriptive models. However, over the last decennia experimental evidence has been accumulating slowly, indicating that this assumption of independency is not a correct one.

Evidence for this interdependence of some of these factors may be encountered at the organ level (e.g., Huijing and Ettema, 1988; Ettema et al., 1990a; Ettema et al., 1990b; Ettema et al., 1992), at the intracellular level (see below) as well as at the level of motor units (see below). Particularly the existence of a sarcomere length dependent sensitivity to calcium ions (e.g., Stephenson and Wendt, 1984) as well as of distributions of mean sarcomere length of different fibres (e.g., Huijing, 1988; Heslinga and Huijing, 1990; Heslinga and Huijing, 1993; Huijing and Baan, 1992; Willems and Huijing, 1994b; de Ruiter et al., 1995), or motor units (e.g., Bagust et al., 1973; Lewis et al., 1972), may indicate a necessity for adaptation of muscle models. The decision if such adaptation of models is necessary, should be made in view of the modelling goals as well as the 
desired level of organisation at which the model output is aimed. The same will be true for the way any changes are incorporated in the model (i.e., a descriptive or an explanatory way). In the present article we will focus on isometric length force characteristics because doing that will already allow us to present a number of important features that should be considered in this type of decision making for muscle modelling.

\section{Factors affecting isometric muscle length-force characteristics}

A distinction will be made between muscles comprised of fibres of identical properties and tendinous elements with homogeneous characteristics on the one hand and a second part muscles comprised of fibres and tendinous elements which are not identical in different locations within the muscle will be discussed. This distinction is not made only for didactic purposes but also because frequently muscle models are constructed according to the first group (e.g., Benninghoff and Rollhäuser, 1952; Gans and Bock, 1965; Huijing and Woittiez, 1984; Huijing and Woittiez, 1985; Woittiez et al., 1984; Otten, 1988; Zajac, 1989; Scott and Winter, 1991; Hawkins and Hull, 1991; Burkholder et al., 1994). As in this type of modelling usually no mechanical interaction between fibres is incorporated it is implicitly equivalent to modelling a muscle as containing one giant fibre.

\subsection{Extracelluar effects: muscle geometry}

Muscle geometry is to be considered one aspect of muscle architecture. In this context muscle architecture is defined as the arrangement of the elements constituting the muscle with respect to each other. A major factor for muscle geometry is muscle volume. As muscles shorten their cross-sectional area increases because of constant volume of the muscle. The constancy of muscle volume was first shown in experiments performed in the late 1660's by Jan Swammerdam (see Kardel, 1994), hut published much later (Swammerdam, 1737) and in more recent times confirmed (Baskin and Paolini, 1967). The notion was enforced by the fact that a constant lattice volume was inferred from X-ray diffraction studies (Huxley and Brown, 1967; Rome, 1967; Elliott et al., 1967; Matsubara and Elliott, 1972). It should be noted that some contradictory evidence is reported for 
volume of isolated fibres (Neering et al., 1991; Taylor et al., 1992; Trombitás et al., 1993).

If bulging and other redistribution of volume of muscle fibres is not taken into account, the increase in cross-sectional area is inversely proportional to fibre shortening, and the only way enough space can be created for the enlarged muscle cross-sectional area is an increase of the angle between the fibre and the attachment site. If the attachment site is allowed to change length further changes of this angle are necessary.

To study effects of muscle geometry it is important to distinguish muscles according to the ways of attachment of its fibres.

Muscle fibres attached to bony elements at both ends

Modelling of muscle geometry and its functional consequences has many times been performed as if muscle was build according to this description, i.e., any elastic effects were excluded (Stensen, 1667; Borelli, 1680; Benninghoff and Rollhäuser, 1952; Gans and Bock, 1965; Huijing and Woittiez, 1984; Huijing and Woittiez, 1985; Woittiez et al., 1984; Burkholder et al., 1994). This type of muscle geometry is very rare but it occurs in some molluscs for muscle which can close the shell. Nevertheless, this type of model has contributed to the understanding of muscular functioning. As we concentrate on modelling of human muscle or muscles of other mammals we can limit considerations to the following: The increase in fibre angles will have enhancing effects for length range of active force exertion (e.g., Huijing and Woittiez, 1984; Huijing and Woittiez, 1985; Woittiez et al., 1984), as well as for shortening velocity of the muscle (e.g., Woittiez et al., 1984; Zuurbier and Huijing, 1993).

Muscle fibres attached to aponeuroses at both fibre ends

A parallel fibred muscle will have relatively long fibres compared to muscle length and a very short aponeuroses. The direction in which the fibres exert force will be almost parallel to that of the muscle. Therefore, fibre angle with the line of pull of the muscle will be negligible but the aponeurosis angle may be sizable (Willems and Huijing, 1994a). For such a muscle the major factors for determining length range of active force exertion as well as shortening velocity will be the same as those determining the properties for its fibres, i.e. number of sarcomeres in series within the fibres and sarcomere length force and force velocity characteristics. This is so because functional effects of changing fibre and aponeurosis angle and elastic effects of the aponeurosis will be most likely be small and therefore negligible. For muscle of much higher degree of pennation the fibres will be short relative to muscle length and the aponeurosis relatively 
long. Fibre angle will be large and aponeurosis angle smaller. For such a muscle major factors for determining length range of active force exertion as well as shortening velocity will still be number of sarcomeres in series within the fibres and sarcomere length force and force velocity characteristics. However because of this muscle geometry both angular effects and elasticity may contribute substantially to muscle length range of active force exertion and shortening velocity. In modelling these features have been worked on by modelling muscle of homogeneous geometry and other properties under conditions of maximal activation.

An important consequence of the (assumed) homogeneity of the muscle would be the scalability of muscle properties as a function submaximal activation duc to recruitment of motor units, identical with respect to length range: Length range of active force exertion and instantaneous velocity of shortening are uniquely related to muscle length. If all the fibres of a muscle have approximately similar characteristics and behave similarly it is expedient to model the muscle as one giant muscle fibre: Many lumped fibre models used in modelling of movement (e.g., Bobbert et al., 1986a; Bobbert et al., 1986b; Zajac, 1989; Thunnisse, 1993) make use of this idea by simply scaling of force of submaximally activated muscle on the basis of maximally activated length force characteristics (Fig. 1). The question if such application may be considered valid will be discussed in paragraphs below.

The heuristic value of modelling homogeneous pennate muscle is apparent: For example for rat gastrocnemius medialis muscle length range between optimum and active slack length for muscle can be understood to be considerably increased compared to that of its fibres. Also even at moderately short muscle lengths rat gastrocnemius muscle fibres will
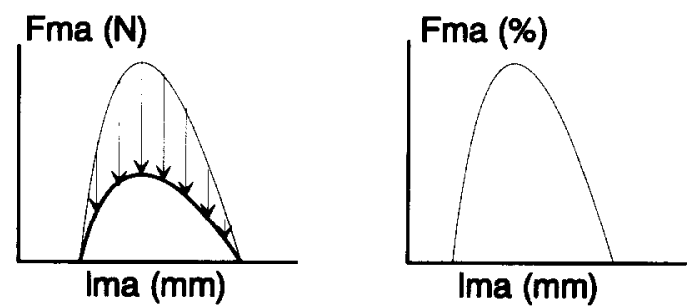

Fig. 1. Scaling forcc. A. schcmatic representation of muscle length force characteristics is shown in the left panel. In muscle modelling frequently estimates of force for submaximally active muscle is obtained by scaling the force of the maximally active muscle linearly for all lengths, i.e., the normalized length force curves of maximally and submaximally active muscle are identical (right panel). 
shorten only at a small fraction of the speed of shortening of the muscle (Zuurbier and Huijing, 1992). Despite the fact that these phenomena have been studied for more than three centuries (e.g., Stensen, 1667) the exact mechanisms determining the angular effects are not understood in every detail (Zuurbier et al., 1994, see also Willems and Huijing, 1994a). Also the elastic or other effects of the aponeuroses are not very well understood as experimentally determined length changes of thc aponcurosis were reported not to be uniform (Zuurbier et al., 1994). On the basis of similar experiments in cat soleus muscle Scott and Loeb (1995) conceived the idea that involvement of the epimysium could lead to artifacts in marker displacement (in their case: sonographic crystals glued to the muscle). Correction for these artifacts led to similar stress-strain properties for tendon and aponeurosis. If this mechanism was also present in the results for other muscles (Griffiths, 1989; Caputi et al., 1992; Zuurbier et al., 1994) can not be excluded and should be investigated. Recent discussion on the electronic mail forum for Biomechanics and movement science (BIOMCHL) indicates that differential length changes within this type of tissue should also be considered.

Particularly angular effects on fibre shortening speed in relation to muscle shortening speed effects, but also the effects on length range of active force generation are very important for muscle functioning. Regarding the level of force, similar arguments have been made by Scott and Winter (1991). Therefore it is clear that the statement by Winters (1995) that effects of muscular geometry have become exaggerated for muscle modelling, is hardly tenable. What could be true that, depending on the modelling goals and the level of organization that these models are directed at, it may not always be necessary to include these effects as explanatory models, but that a descriptive approach may suffice.

\subsection{Intra-sarcomere effects}

\section{Length dependent $\mathrm{Ca}$ sensitivity}

Development and application of techniques for obtaining isolated fibres allow study of muscle on the level of the fibre in addition to the level of the organ. Comparison of results of these two types of my muscle research allows identification of mechanisms active at the cellular level and at the organ level. Studying skinned muscle fibres have the additional advantage that the contractile apparatus can be studied under conditions in which the "milieu interne" of the sarcomeres could be manipulated in experiments. 


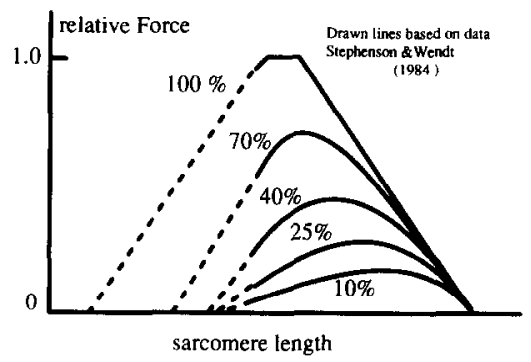

Fig. 2. Effects of myofibrillar length dependent $\mathrm{Ca}^{2+}$ sensitivity. Schematic representation of length force data plotted for sarcomeres in skinned fibres of rat extensor digitorum longus muscle (modified from Stephenson and Wendt, 1984). The percentages identify length force curves of the fibre at the indicated value of maximal calcium concentration. Note that as calcium concentrations are decreased, not only force decreases but sarcomere optimum length and active slack length (i.e., the lowest length at which force can be exerted) shift progressively to higher length. The maximal length of active force exertion remains unchanged.

First, temperature effects were studied (Stephenson and Williams, 1981). Later a length dependent myofibrilar sensitivity to calcium was discovered (Stephenson and Wendt, 1984; Stienen et al., 1985; de Beer et al., 1988).

Experimental evidence indicates that myofibrillar proteins are not equally sensitive to calcium at every sarcomere length. A functional consequence of this length dependent calcium sensitivity is that at lower calcium concentrations sarcomere optimum length and probably also active slack length are shifted to higher lengths (Fig. 2). Of course if the length force characteristics of sarcomeres are dependent on intracellular calcium concentration, this will also be the case for length force characteristics of fibres and muscle.

\section{Consequences of length dependent calcium sensitivity. Firing frequency}

Examples of length dependent calcium sensitivity effects on muscle length force characteristics can be found in the literature in which these characteristics are studied as function of stimulation frequency (Rack and Westbury, 1969; Rome et al., 1985; Roszek et al., 1994). If stimulation is performed at a lower frequency force will generally be lower. Rome et al. (1985) concluded that this lower force did not lead to substantially altered sarcomere length force properties. However, Rack and Westbury (1969), Roszek et al. (1994) and Roszek and Huijing (1995) found that, as stimulation frequency is lower, the ascending limb of the length force curve of fully 

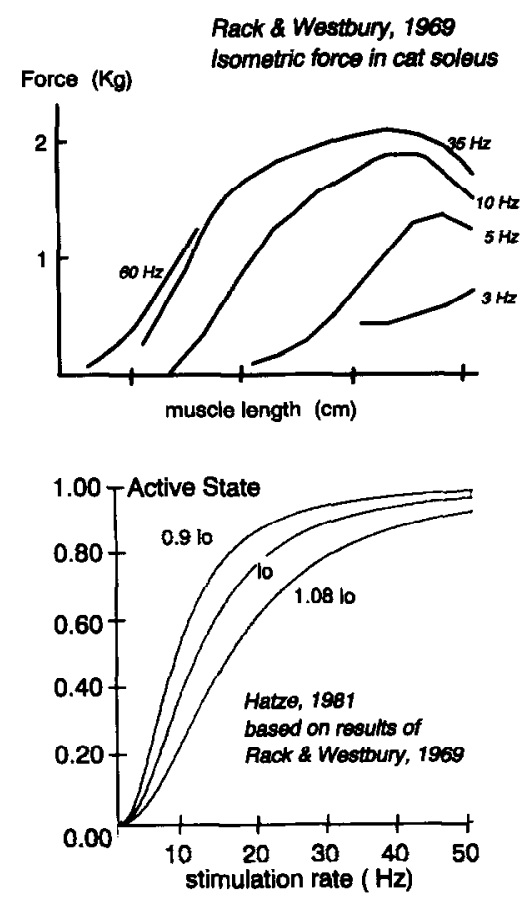

Fig. 3. Effects of varying stimulation frequency on muscle length force characteristics. Top panel: schematic representation of data obtained by Rack and Westbury, 1969. Note that for lower stimulation frequencies force is lowered and optimum length shifts to higher lengths. Estimates of muscle active slack length would also show such a shift. Lower panel: Normalized force as a function of stimulation frequency for different muscle lengths at or near optimum length $\left(l_{\mathrm{o}}\right)$. These curves were constructed for modelling purposes by Hatze (1981) on the basis of data shown in the top panel, and incorporated into a muscle model. It should be noted that variation of length normalized force characteristics is implicitly described as a function of stimulation frequency for the lengths indicated.

recruited muscle is shifted as a whole to higher lengths. This means that muscle optimum length and muscle active slack length both will occur at higher lengths at submaximal stimulation (Fig. 3). In muscle modelling a notable exception to the rule that such effects are neglected is the work of Hatze (1981), in a which length dependent stimulation rate-force curve is incorporated in the model (Fig. 3). Such curves implicitly define alterations of length force characteristics as described above.

\section{Fatigue}

In general, muscle fatigue is defined in an operational way by its effect: the failure to maintain the required or expected power or force output (e.g., Allan et al., 1992; Fitts, 1994). In case of electrical stimulation of 
muscle or nerve the definition is extended with the condition of constant input (Levy et al., 1990). Despite the fact that length force characteristics are considered very important determinants of muscle functioning capability, little attention has been focused on this aspect. This is probably the case because attention has been drawn mainly to the many mechanisms (see Sjøgaard, 1991; Sahlin, 1992; Enoka and Stuart, 1992; Allan et al., 1992; Grassino and Clanton, 1993; Fitts, 1994) implicated in this complicated phenomenon, but also because the general description of fatigue is given only in terms of decrease of force during sustained or repeated contractions at one or at best only a few muscle lengths. In muscle modelling this has resulted, if attention was given to fatigue at all, in simple grading of length force characteristics of the fatigable segments of the fibre population (Hawkins and Hull, 1993).

Some recent work in muscle fatigue has focused on changes of sensitivity of myofibrilar proteins to calcium ions in intermittent contractions and on inhomogeneities within the muscle fibre concerning calcium release from the sarcoplasmatic reticulum during the process of excitation contraction coupling (Westerblad et al., 1990; Westerblad et al., 1991; Allan et al., 1992). It is useful to make this distinction because two different mechanism are active in the development of fatigue: During intermittent contraction the intracellular calcium concentration is lowered but remains homogeneous throughout the cell, whereas during sustained contraction the calcium concentration is lowered more in the centre than at the periphery of the cell (Westerblad et al., 1991; Allan et al., 1992). Because of the length dependent calcium sensitivity described above, not only is a decrease in force expected but also changes of the length force characteristics: At lower calcium concentrations the ascending limb of the length force curve will be shifted to higher lengths. Because of this effect the relationship between decrease of force and the actual cause of fatigue is highly non-linear. The effects of this phenomenon are illustrated schematically in Fig. 4. In the left panel the muscle length dependent force for two intracellular compartments are distinguished : the inner and outer ones. In unfatigued active fibres, $\mathrm{Ca}^{2+}$ concentration is homogeneous throughout the cell so compartment length force characteristics are identical. The total force is calculated by adding the forces exerted by the compartments. The middle panel shows length force characteristics of the fatigued fibre. For the outer compartment $\left[\mathrm{Ca}^{2+}\right]$ unchanged and consequently also the length force curve. For the inner compartment $\left[\mathrm{Ca}^{2+}\right]$ is lowered so effects of myofibrillar length dependent calcium sensitivity are encountered: Opti- 

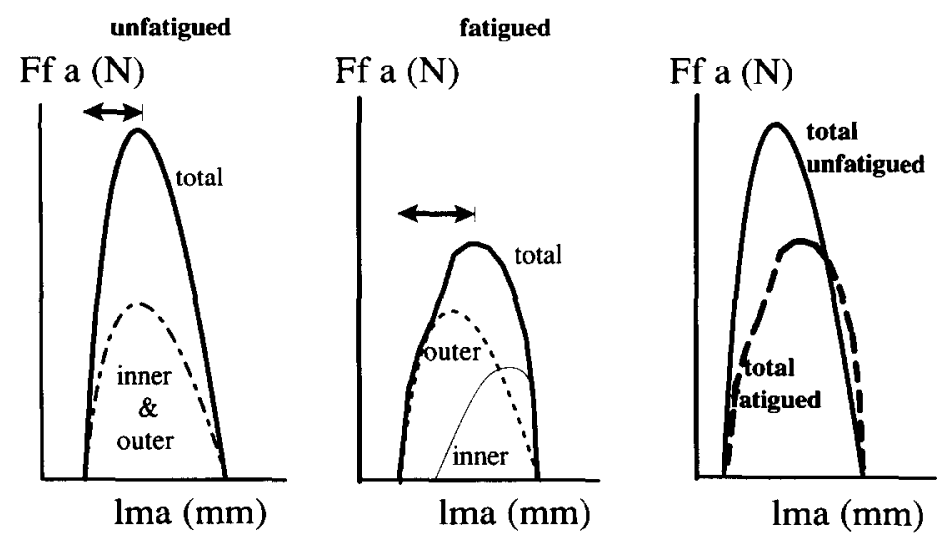

Fig. 4. Schematic representation of a possible mechanism for fatigue induced changes of length force characteristics during sustained contraction.

mum and active slack lengths shift to higher muscle lengths. Summation of the force for each muscle length yields total fibre force. A comparison between length force curves for the fatigued and unfatigued state is made for the hypothetical fibre. Note that active slack length and maximal length of active force exertion are unchanged but that the shape of the curve for the fatigued fibre is altered in such a way as to shift optimum length somewhat to higher lengths.Experimental evidence compatible with such a mechanism during sustained contraction is available for rat muscle Fig. 5. (Huijing and Baan, 1995). Note that, due to the shift in optimum length, the magnitude of fatigue induced decrease of force is very much dependent on muscle length.

\section{Potentiation by firing rate history}

The term potentiation is generally used for situations in which a higher force is found than expected on the basis of a description of the instantaneous external circumstances under which a muscle is active. It is encountered for example as post-tetanic potentiation for the amplitude of twitches performed a certain time after a tetanic contraction (Allan et al., 1992; Fitts, 1994), or even an increased force exerted in a concentric as well as isometric phase of contraction following an initial eccentric phase (Cavagna, 1977; Ettema et al., 1990a; Ettema et al., 1990b; Ettema et al., 1992). It is clear that the mechanism of the increased force is not necessarily the same and may not involve calcium concentration in these circumstances. An 


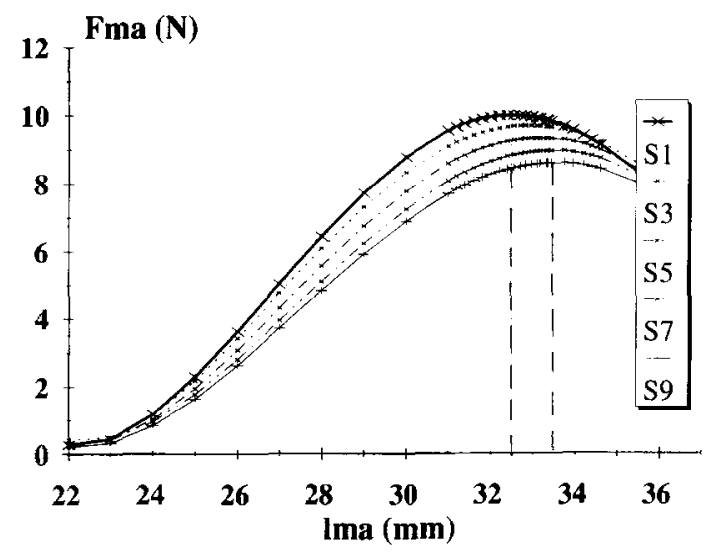

Fig. 5. Experimental data for rat medial gastrocnemius muscle length force characteristics as obtained for sustained contractions of $2 \mathrm{~s}$ (Huijing and Baan, 1995). Force and muscle length were sampled every $200 \mathrm{~ms}$ (S1 through S9) after the onset of supramaximal stimulation of the Ischiadic nerve. Note the progressive decrease of force due to fatigue and the progressive shift of optimum length to higher lengths.

example of this is the interaction between aponeurosis length and fibre length due to elastic effects at higher muscle forces (Ettema et al., 1992).

Despite that fact, it is very likely that in potentiating phenomena often calcium concentration is implicated in an important role since it is a mediator of muscle activation. In cases where this is true, as with decreasing firing frequencies, potentiation will affect length force characteristics of muscle not only with respect to the magnitude of the force exerted, but also regarding the relative position of the length force curve with respect to the length axis (e.g., Roszek et al., 1994; Roszek and Huijing, 1995). Decreasing firing rates are encountered frequently in human muscles during sustained contractions (Marsden et al., 1983). Fig. 6 shows that, for a decreasing stimulation rate staircase, optimum length shifts to higher lengths for lower frequencies but active slack length is affected to a very small extent at most. It should be noted however that, compared to equally low but constant stimulation frequencies, optimum length is not shifted as much to higher lengths (Roszek et al., 1994; Roszek and Huijing, 1995). As a consequence force particularly at lower muscle length is highly potentiated in the decreasing frequency staircase. It is conceivable that this would be caused by higher calcium concentrations remaining in the cell due to a certain time needed to pump $\mathrm{Ca}$ back to the sarcoplasmatic reticulum. However if only increased calcium concentrations would play a role, length 


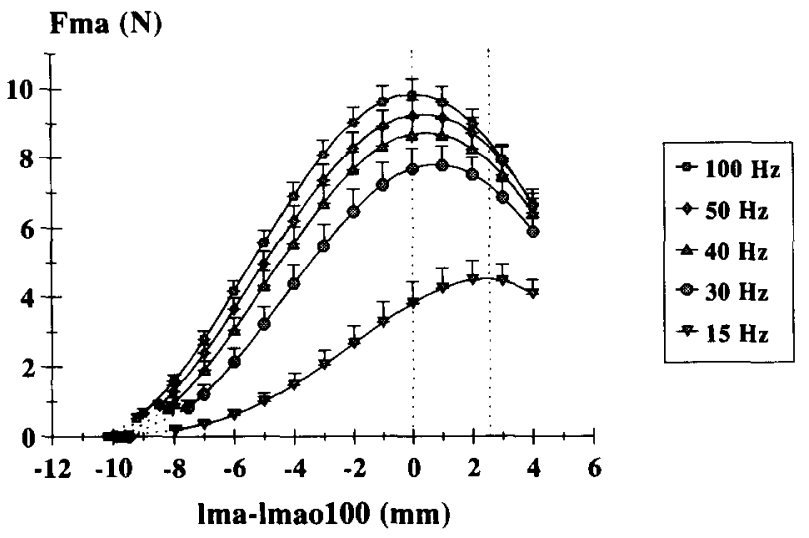

Fig. 6. Length force curves for rat medial gastrocnemius muscle for contractions with decreasing stimulation frequency staircases performed at different muscle lengths. Muscle length is indicated as deviation from the length at which optimum force was encountered for the $100 \mathrm{~Hz}$ stimulation frequency (lmao100). Note that as the frequency is decreased force decreases and optimum length shifts substantially and progressively to higher lengths whereas active slack length changes only very little at best. As a consequence particularly at lower lengths force exerted remains much higher than would expected on the basis of equally low but constant stimulation frequency.

force characteristics obtained during decreasing and constant stimulation protocols would be identical, if optimum muscle lengths would be superimposed and optimum force normalized. Analysis indicates that this is not found (Roszek and Huijing, 1995). One important reason for this is the fact that muscle active slack length is shifted only very little to higher lengths if the muscle is stimulated at low frequencies in a decreasing stimulation frequency staircase (Roszek and Huijing, 1995). A higher force is maintained for a decreasing stimulation rate protocol than for a constant stimulation rate protocol for at least several seconds. Unpublished observations from our laboratory indicate that even if a decreasing stimulation frequency staircase is followed immediately by an increasing staircase in principle for muscle active slack length the situation remains similar but optimum muscle length shifts back in the direction of that of high frequencies. Therefore, other factors than calcium per se must be involved as well.

Considerable evidence (reviewed by Sweeney et al., 1993) exists for implication of phosphorylation of part of the myosin molecule (myosin light chain) to this phenomenon. For details on myosin structure the reader is referred to Lowey (1986). That phosphorylation of part of myosin light chain is implicated in this type of potentiation has been clear since the 
work of Manning and Stull (1979). In the last decade it has become clear (Sweeney et al., 1993) that this phosphorylation shifts $\mathrm{pCa}$-force curve, which in principle is comparable to the frequency force curve, to lower concentration (or frequency) values and may alter its shape by becoming steeper, i.e., myofilaments become more sensitive to calcium. For a given firing frequency both the amplitude of force generated and the rate of force development as well as stiffness is increased. The fact that the myosin heads move away from thick filament back-bone seems to be implicated in this. It is also clear that the enzyme that regulates this phosphorylation (myosin light chain kinase) is activated very much faster by increasing $\mathrm{Ca}$ concentrations than it is deactivated by rapidly decreasing calcium concentrations. Depending on the activity of the enzyme that removes the phosphor groups (myosin light chain phosphatase) a high degree of phosphorylation may persist even though calcium concentrations may have dropped. In other words the phosphorylated myosin light chain may act as a memory for higher firing rates.

As the rate of activation of the kinase enzyme is very high for higher firing rates a relatively short period of activity at these rates may influence "the memory" substantially.

These phenomena cause the length range between optimum and active slack lengths to be quite variable depending on the actual firing rate conditions as well as their short term history. As a consequence the force at a particular muscle length may be highly variable in these circumstances, particularly if the ascending limb of the length force curve is considered.

\section{Effects of previous length changes of active muscle}

Excentric contraction. The potentiating effects on concentric or isometric muscle force of a preceding excentric phase of the contraction is well known (Edman et al., 1978; Edman et al., 1982; Cavagna, 1977; Ettema et al., 1990a; Ettema et al., 1990b; Ettema et al., 1992). It is also quite clear (Edman et al., 1978; Ettema et al., 1992) that this type of potentiation occurs predominantly at higher muscle lengths (i.e., near or particularly over optimum lengths where the magnitude of the effect increases). This means that length force characteristics of fibre and muscle are likely to be changed: At the higher lengths, force is increased and as a consequence optimum muscle length shifts to higher lengths (Ettema and Huijing, 1994b, see for example their Fig. 1). These effects on the length force 
curves need to be described in more detail as our present understanding is based on a very limited number of experiments.

Concentric contraction. The fact that shortening has a decremental effect on muscle force during subsequent isometric contractions has been known for decades (Buchtal and Kaiser, 1951; Abbot and Aubert, 1952; Deleze, 1961; Bahler et al., 1968; Joyce and Rack, 1969; Marechal and Plaghki, 1979; van Ingen Schenau et al., 1988) but has found almost no application in muscle and movement modelling. This effect is present regardless of the nature of the shortening phase of the contraction (isokinetic or isotonic contraction). This post-shortening decrease of force is accompanied by a decreased stiffness (Sugi and Tsuchiya, 1988), which lead to the idea that shortening in some way decreases the number of attached crossbridges. The mechanism by which this decrease of force is effected is not clear at all. Edman (1975); Edman, 1980) reported a deactivation of fibres due to shortening, but that phenomenon seems to be limited to twitches. Edman et al. (1993) implicated the role of distribution of sarcomeres in series within a fibre: Shortening performed at lengths over optimum length induced a larger distribution of sarcomere length within one fibre than below optimum length, so that a correlation could be shown between the magnitude of inhomogeneities of sarcomere length in series and post shortening force decrease. Granzier and Pollack (1989) found that only part of the post shortening force decrease could be explained by in series inhomogeneity of sarcomere length, as they also saw the effect in fibre segments of homogeneous sarcomere length. It is clear that regarding mechanism as well as functional consequences further work is necessary. The question needs to be asked if the effects of excentric and concentric length changes of active muscle are opposite effects of the same mechanism. Regarding possible mechanisms the issue needs to be addressed if this phenomenon can be reconciled with the sliding filament theory. Particularly the study of the effects of previous shortening on isometric length force characteristics is important to evaluate functional consequences. A start of this type of work was made recently by Vance et al. (1994) for load moving contractions and by Meijer et al. (1995) for isokinetic and isotonic contractions. From this work it is already apparent that isometric length force characteristics are different after shortening, and that several aspects of history of shortening influences these important muscle mechanical properties. In his contribution to this issue Winters (1995) makes the statement that certain basic physiological experiments 
(such as length ramp and hold protocols) "have very little value for most voluntary movements". Even though it may be true that such results may not yield the type of parameters that modellers may be looking for, it is clear that if these experiments indicate as substantial changes in mechanical properties as they do, they are crucial for the understanding of mechanisms and effects active in voluntary movement and thus also for modelling voluntary movement.

During a concentric contraction at constant activation, actual force is of course determined by both instantaneous length and velocity effects. The idea was conceived in our laboratory (Meijer et al., 1995, unpublished observations) that isometric length force characteristics that partly govern mechanical behaviour of the muscle during a concentric contraction can be reconstructed on the basis of isometric length force curves which were made for contractions with the appropriate shortening history. As this idea is executed even more substantial changes of length force characteristics are encountered particularly at lengths near and well over optimum length were force remains relatively constant.

The fact that shortening history seems to have such profound effects has another very important implication for modelling of muscle and movement as well as experiments in the realm of force velocity characteristics. Experimentally the different points, on the basis of which of the force velocity curve is constructed, were obtained by executing protocols in such a way that a target muscle length was reached at different velocities either isotonically or isokinetically. It is impossible to do this without imposing different shortening history as evident from parameters such as starting length and range of shortening which seem to affect length force properties so substantially. Therefore force velocity curves obtained in this way do not show exclusively the effects of velocity on force exerted, but rather the nett effect of interaction of changed length force characteristics with velocity effects. This expected to be of particular importance for force velocity curves for higher muscle lengths (just under optimum length and higher).

\subsection{Conclusion I}

From the above it is clear that even for fully recruited homogeneous muscle the effects of degree of activation and muscle length force characteristics are not independent factors. Short term history of activation and shortening and lengthening of a muscle are very important factors. The shape of the length force curve is thoroughly affected by both history 
effects, however the effects of previous shortening most fundamentally alters the length force curve. Therefore, descriptive or explanatory modelling of muscle, particularly those with predictive purposes, is not very likely to be successful unless the nonlinear effects of myofibrilar length dependent calcium sensitivity and its history as well as shortening and lengthening history are taken into account.

For muscle modelling the combination of firing rate effects, and shortening history effects will yield one additional important phenomenon: Positive slopes of the length force curve slopes are encountered at very much higher lengths than would be expected on the basis of the sliding filament theory. Many instability problems of muscle models may be prevented by incorporating this featurc in some way. It may preclude the necessity of manipulating parameters that sometimes is performed to get models working.

Because of the described history effects is clear that muscle (or limb) stiffness may not be assumed to be simply and uniquely related to muscle activation as is frequently done in studies of motor control (for a description see, e.g., Gielen et al., 1995).

\section{Non uniformly build muscle: distributed properties}

In the previous paragraphs properties of fully and partially activated were discussed for homogeneous muscle, in which all fibres were maximally or submaximally active. It is quite clear that fully homogeneous muscle do not exist. Therefore, in the paragraphs below attention will be focused on several aspects of inhomogeneity and functional consequences. A distinction will be made between muscles that are fully recruited and those that are partially recruited. In the former all fibres are active and in the latter only a segment of the fibres (motor units) are activated.

\subsection{Sarcomere effects}

Ca sensitivity of fast and slow sarcomeres

Stephenson and Williams (1981) studied the effect of temperature on the calcium - force curves of skinned fibres and concluded that characteristics of the calcium - normalized force curve are very different for sarcomeres of fast and slow fibres. Implications for sarcomere length force characteristics should be worked out. 


\section{Distribution of sarcomere length}

The phenomenon of distributions of sarcomere length was reviewed recently (Huijing, 1995). Below the most salient features will be indicated. Two types of distributions of sarcomere lengths can be distinguished:

1. Within one fibre, lengths of sarcomeres in series may not be identical: The sarcomeres at the ends of the fibre tend to be shorter than those in the centre segment (Gordon et al., 1966a). As a consequence feedback mechanisms controlling are used to study isometric sarcomere length force properties (e.g., Gordon et al., 1966b). If so called fixed end contractions are induced complicated mechanical interactions will take place between sarcomeres arranged in series, causing at least the descending limb length force characteristics of an isometric fibre(-segment) to be fundamentally different from sarcomere length force curves (e.g., Granzier and Pollack, 1990; Pollack et al., 1993): It has the effect at least on the descending limb of the length force curve to increase the length range between optimum length and maximal length of active forcc cxcrtion. As a consequence fibre length force characteristics will deviate substantially from those predicted by sliding filament approaches (e.g., Zuurbier et al., 1995). Particularly for models that use fibre or contractile element length force characteristics in a descriptive way this may be highly relevant.

2. If sarcomere length within a fibre is averaged, mean sarcomere length of different fibres of a muscle may be compared.

\section{Primary distribution of fibre mean sarcomere length}

One may visualize a distribution of mean sarcomere length simply by altering the number of sarcomeres in series for a selection of fibres within a muscle without changing the length of those fibres or the muscle (Fig. 7). It is clear that a distribution of sarcomere length will be introduced this way. Such a distribution will be referred to as a primary distribution of mean sarcomere length. Such a distribution is referred to as a primary as it is the consequence of a change of muscle architecture. The functional effects of introducing such a primary distribution may be visualized by shifting fibre length force curves along the axis of muscle length combined with an increase of fibre length range of active force exertion.

This primary distribution may be a very important factor determining the length range of active force generation of the fully recruited muscle: Willems and Huijing, 1994a; Willems and Huijing, 1994b; Willems and Huijing, 1995 showed for rat semimembranosus muscle that length range 


\section{Primary dlstrlbution of fibre mean earcomere length}
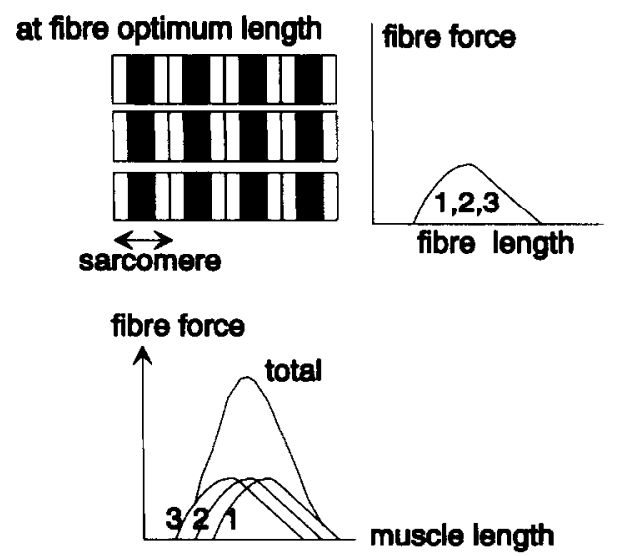

Fig. 7. Schematic illustration of the concept of primary distribution of fibre mean sarcomere length. Three identical fibres are indicated in the top part of the figure: Identical sarcomere length force curves and number of sarcomeres in series cause identical fibre length force characteristics. If these fibres are mounted within a muscle such that their optimum lengths are distributed with respect to muscle length (lower panel) a primary distribution of mean sarcomere length is obtained at any muscle length. The effects on the muscle length force curve is a lower than maximally possible force at muscle optimum length and an increased length range of active force exertion.

between optimum and active slack lengths of individual muscles did not correlate with number of sarcomeres encountered within fibres, but did correlate highly with a variable estimating the magnitude of the distribution of mean sarcomere length of fibres. This means that individual variation of this length range is to a large extent explained by individual variation in distribution of mean sarcomere length: In that study between almost zero and up to $1 / 3$ of the muscle length range between optimum and active slack length should be ascribed to this distribution of sarcomere length. The fact that these muscles were easily damaged just over optimum length (Willems and Huijing, 1995) may be related to the primary distribution. Damage encountered in some fibres occurred in sarcoplasmatic reticulum near the surface of the fibre (Willems, Huijing and Friden, unpublished observations (see also Willems, 1994). Such possible effects of the distribution should be taken into account when considering the cause of the damage (e.g., Lieber and Friden, 1993).

It should be noted that active slack length of this type of muscle is determined by one group of fibres, namely the fibres that can still generate 
force at the lowest muscle length, whereas optimum muscle length will be determined by the mean of optimum lengths of all fibres, weighed for the contributions of force. As a consequence for a muscle with a primary distribution, any change in contribution of force of a segment of the fibre population (due to for example fatigue, potentiation or submaximal activation) will lead to at least some change of muscle optimum length (Huijing, 1995). In the experimental results described in the first segment of this article these effects are present as well as those discussed explicitly.

\subsection{Effects of muscle geometry}

Muscle fibres attached to aponeuroses at both ends

Considerable evidence is available indicating that the geometry of pennate muscle is not completely uniform (e.g., Beritoff, 1925; Benninghoff and Rollhäuser, 1952; Rollhäuser and Wendt, 1955; Willemse, 1963; Heukelom et al., 1979; Woittiez et al., 1984; Huijing, 1985; Gans and de Vree, 1987; Otten, 1988; Gans and Gaunt, 1991; van Leeuwen and Spoor, 1993; Zuurbier and Huijing, 1993; Ettema and Huijing, 1994a; Willems and Huijing, 1994a; Willems and Huijing, 1995) and that this has consequences for in vivo movement (Hoffer et al., 1992). Despite this evidence, in muscle modelling many investigators, who include effects of geometry in their models, choose to disregard this aspect (e.g., Stensen, 1667; Borelli, 1680; Pfuhl, 1937; Benninghoff and Rollhäuser, 1952; Gans and Bock, 1965; Hatze, 1981; Huijing and Woittiez, 1984; Huijing and Woittiez, 1985; Pierrynowski and Morrison, 1985; Otten, 1988; Zajac, 1989; Spoor et al., 1991; Hawkins and Hull, 1991; van Leeuwen, 1992; Burkholder et al., 1994). It is clear that in many cases heuristic aims of modelling work lead to this attractive simplification, or it is thought that relative to the errors that will be made inevitably in modelling the effects of this simplification will be minor. Even though this may be true one should realize that a major principle in muscle will change: The mean sarcomere length of different fibres will not necessarily be equal any more.

Even though many of the muscle models describing the effects of muscle geometry are explanatory types regarding muscle geometry, a major cause of difficulties with these models is most likely that they do not model events that take place within the muscle mechanically: Force is introduced only as a function of fibre length, which is obtained as a function of muscle geometry, and assumed fibre length force characteristics. Van Leeuwen and Spoor (1992) argued that this has led to many muscle models which are 
not mechanically stable. For the detailed study of mechanics of pennate muscle it is clear that more mechanically oriented muscle models are required which incorporate sufficient physiological characteristics. A finite element analysis of muscle, such as the one for which preliminary results have been presented by Otten (1994) and van der Linden et al. (1995), is indicated. Recently a meeting of dutch biomechanics groups (to be reported (1995) in a spccial issuc of the European Journal of Morphology) showed a very high density of groups working on this type of models in the Netherlands. Within the limitations of their assumptions such models will allow a more appropriate handling of interactions of forces along the line of pull of the fibres and perpendicular to it, as well as interactions between fibres. By doing so it is expected that bulging and/or curving of muscle fibres or aponeuroses and functional consequences will be understood better. One thing these types of models show quite clearly: Even if muscle geometry is modelled to be homogenous initially (i.e., equal fibre lengths, fibre mean sarcomere lengths, fibre angles, etc.) a distribution of fibre length and fibre mean sarcomere length and fibre angles will develop due to interaction between fibres, and fibres and elastic tissue elements (Otten, 1988; van der Linden et al., 1995; Huijing, 1995). Because these variation of mean sarcomere length of fibres is an effect secondary to the effects of several factors such as those discussed below we will refer to this phenomenon as: secondary distribution of fibre mean sarcomere length (Huijing, 1995). Such a secondary distribution can be visualized by a widening of length range of active force exertion of certain (groups of) fibres.

For example differences in angular effects of pennation (e.g., Zuurbier et al., 1994) and/or aponeurosis compliance (e.g., Bobbert et al., 1990; Zuurbier et al., 1994) will lead to differences in the relationship between muscle length and mean sarcomere length for different fibres with equal number of sarcomeres in series. Another factor will be curving of fibres and aponeuroses (Heukelom et al., 1979; Otten, 1988; van Leeuwen and Spoor, 1993; Zuurbier and Huijing, 1993; Willems and Huijing, 1995) which will also introduce such a distribution of fibre length and thus possibly of mean sarcomere length of different fibres. Finite element modelling confirms this (e.g., van der Linden et al., 1995, see also Huijing, 1995).

Muscle length force characteristics of fully recruited muscle will be influenced to some extent by this secondary distribution of sarcomere length: The length range of active force generation will be enhanced more at the expense of force exerted at optimum muscle length (Fig. 8) than was expected on the basis of angular and elastic effects in homogeneous 


\section{Secondary distribution of fibre mean sarcomere length}
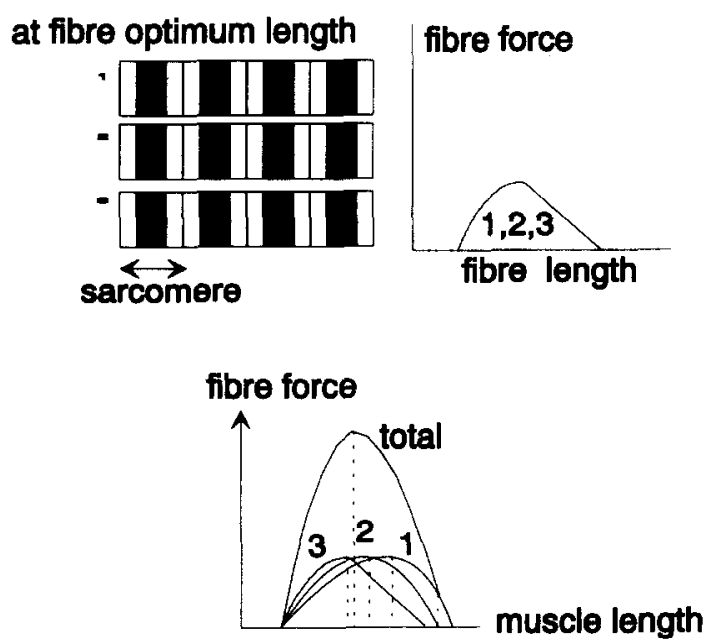

Fig. 8. Schematic illustration of the concept of secondary distribution of fibre mean sarcomere length.

muscle. In the top part three identical fibres are indicated: Identical sarcomere length force characteristics and number of sarcomeres in series cause identical fibre length force characteristics. If these fibres are mounted within a muscle such that for a given length change of muscle a variable smaller length change is found for each fibre a secondary distribution of fibre mean sarcomere length will be introduced. These differences in the deviation of fibre length changes from muscle length changes may be caused by variable contributions of changes of fibre angles or variable elastic contributions to muscular length changes. The latter condition is used in the lower panel. The effect is that, as a function of muscle length, the length range of force exertion of each fibre is increased. This leads to an increased muscle length range of active force exertion, at the expense of a somewhat decreased optimum force.

Therefore, the uniform muscle assumed in the first part in this article partially for didactic purposes, is not likely to exist in biological reality.

During the discussions at the biomechanics meeting indicated above it was pointed out by Dr. Otten that, in addition to the mechanisms discussed above in the paragraph on the effects of stimulation frequency, elastic effects particularly for fibres at proximal and distal ends may affect the stimulation frequency experimental results: Due to the ripple in the force, 
which may be substantial at lower stimulation rates, the length of elastic tendons and aponeuroses will vary somewhat in time. The length of muscle fibres in series with these elastic structures will also vary by a small amount. As an extension of the finite element modelling results it is clear that differences may exist within the muscle regarding this effect for fibres at different locations within the muscle. As a consequence the fibres may not be completely isometric within the isometric muscle tendon complex. In such a case effects of shortening velocity would have to be accounted for. Further work aimed at quantitatively separating these velocity effects as well as consideration of such behaviour for in vivo circumstances (i.e., non-synchronized firing of motor units) is clearly necessary to be able to determine their relative importance.

Winters (1995) has argued that performing the intricate finite element modelling is "perhaps of interest to anatomist, will be of limited value to the system's bioscientist interested in multi-joint coordination". It is very likely true that such finite element models are too complex and time consuming to run to be incorporated in modelling coordination of movement. Even if it would be feasible the model would be so complex that in the case its predictions would deviate substantially from reality, nothing could be learned from the model, and it would have lost even its heuristic value. On the other hand if the functional effects (e.g., increasing the length range of active force generation) would be neglected, particularly at lower muscle lengths, substantial underestimation of forces exerted may occur. The only solution (as suggested also by Winters (1995)), is descriptive modelling. This may be possible since, for a given level of activation, angular and elastic effects are quantitatively related to either actual muscle or fibre lengths. In effect such an approach has been widely used by manipulating muscle length force curves by shape factors (e.g., Otten, 1988; Hatze, 1981; Thunnisse, 1993). The problem then becomes to what extent the descriptive length force curve should be manipulated for different muscles active in human or animal movements studied.

A very important property of muscle with fibres attached to two aponeuroses, which are in turn attached to bone by tendons, is the fact that the external tendons cannot maintain a moment in the absence of additional external forces. Therefore, the external tendons will always be aligned, unless gravity or retinaculi (connective tissue bands, which have effects similar to that of a pulley) or pressure by neighbouring muscles provide such an external force.

As a consequence rotation of the muscle at constant length around its 


\section{A. muscle fibres with two aponeuroses}
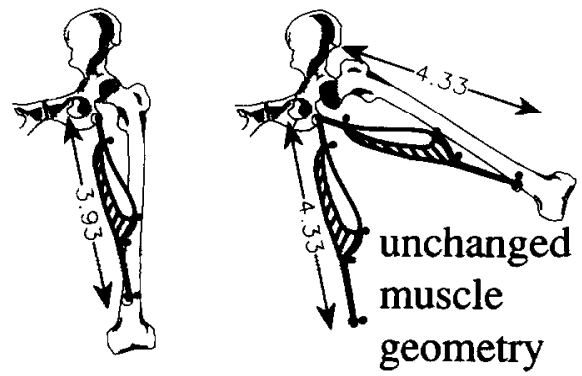

B. muscle fibres with one aponeurosis and one bony attachment
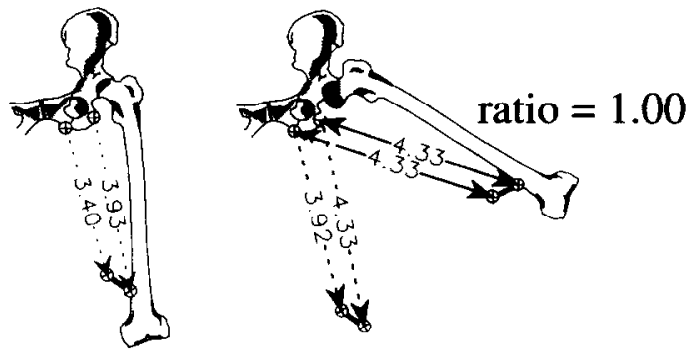

$$
\text { ratio }=1.15 \quad \text { ratio }=1.10
$$

Fig. 9. Schematic representation of effects of rotation of a muscle with respect to its origin for: (A) A hypothetical muscle whose fibres attach at both ends to aponeuroses which are continuous with external tendons; (B) A hypothetical muscle whose fibres attach with one end to an aponeurosis but with the other end directly to bone (right panel).

origin or insertion will not affect the geometry of the muscle (Fig. 9A). Any primary distribution of fibre mean sarcomere length will also be unchanged by the rotation of the muscle. The only change that may be observed, if the bony attachment of the tendon does not have a very small area, will be a small change of length force properties of the tendon due to rearrangement of the length of different tendinous fibrils (for an example of this type of effect see Jansen et al., 1995). As during movement rotation of the segment to which the muscle is attached will not take place around the origin or insertion of the muscle but around a joint axis located at a distance, the muscle will have to shorten to cause such a rotation (Fig. 9A). 
For the effects on muscle force exerted during constant activation angular and elastic effects, as well as effects of secondary distribution of fibre mean sarcomere lengths will have to be taken into account in an identical way as during experimental determination of length force characteristics of in situ muscle in which on shortening the muscle redistributes itself along a fixed external line of pull. This is true for monoarticular as well as a biarticular muscle of the typc indicatcd: there will be a determined relationship between length of the muscle-tendon complex and the angle of the joint or joints that are crossed by the muscle because of the independence of the effects on length changes caused by either joint (Grieve et al., 1978; Visser et al., 1990). As a consequence length force characteristics of these types can be described relatively well as a function of joint angle(s).

Muscle fibres attached with one end to aponeurosis and the other end to bone A large fraction of muscles of the body have their fibres attached at one side to bone. Even though some short elastic fibres are involved in anchoring the fibres into the bone, it is clear that mechanical properties of such an attachment will be very different from that of fibres onto an aponeurosis.

Only few authors provide evidence of their awareness of the fact that such architecture may have functional consequences (e.g., Otten, 1988; Willems and Huijing, 1994a; Willems and Huijing, 1994b; Willems and Huijing, 1995). The straight or curved line of pull of such a muscle may intersect the bony plane of attachment at any location depending on the distribution of forces exerted by the individual fibres (Willems and Huijing, 1994a; Willems and Huijing, 1995). So in contrast with muscles of which fibres are connected to two aponeuroses the muscle line of pull, around which changes of muscle geometry take place, will not be in a relatively fixed position but it may wander throughout the muscle.

Even more important may be effects of a feature illustrated schematically in Fig. 9B: A hypothetical muscle whose fibres attach with one end to an aponeurosis but with the other end directly to bone (right panel). If a muscle of this type is rotated around a point on its bony origin different aspects of muscle architecture will change: The geometry of the muscle is affected by changing fibre angles with respect to the bony origin as well as the relation between lengths of different fibres. As a consequence any distribution of fibre mean sarcomere length is affected. As no changes of muscle length are involved this must be considered changes of the primary distribution of this parameter. The effect is governed by differences be- 

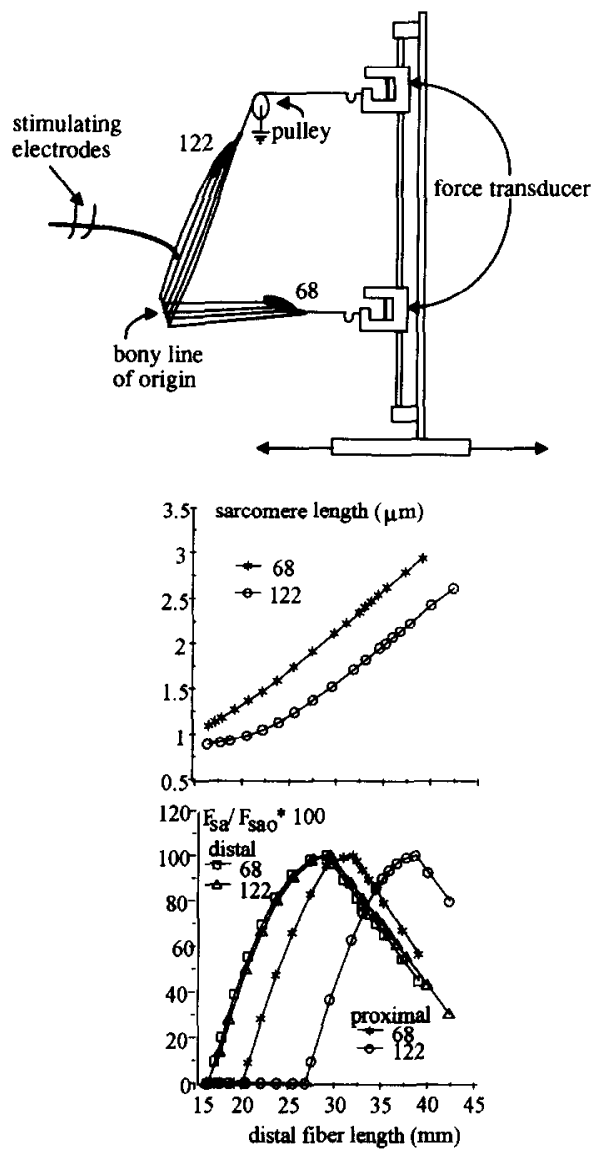

Fig. 10. Experimental evidence for maximally active rat semimembranosus lateralis muscle that primary distribution of fibre mean sarcomere length is manipulated by rotation of the muscle with respect to its bony origin.

tween the moment arms of the different fibres with respect to the axis of rotation.

During in vivo performance of movement, the rotation will not take place at the origin of the muscle but at the joint axis located at some distance, therefore the muscle needs to shorten also, which will involved additional changes of the distribution of fibre mean sarcomere length. As this change is associated with muscle shortening it is considered a secondary distribution. It is concluded that the effects of joint movement involve not only a secondary distribution but also changes of primary 
distribution of fibre mean sarcomere length. As the movement progresses length force curves of (groups of) fibres are shifted along the length axis. For rat semimembranosus muscle experimental evidence for the presence of such phenenomena is available (Willems and Huijing, 1995) and is illustrated in Fig. 10. The top panel shows schematically the experimental setup (superimposed for the two conditions). The numbers identifying the conditions ( 122 and 68 , respectively) relate to the angle that the muscle makes with its bony origin. Muscle length is changed by moving the force transducer holder. The middle panel shows mean sarcomere lengths for proximal fibres as a function of distal fibre length. Note the substantial change caused by muscle rotation. The bottom panel illustrates the functional effects of this: In the specific example distal fibre length-sarcomere force curves (assumed on the basis of myofilament length parameters) remain unchanged, but for the proximal fibre the curve is relocated relative to the length axis as a function of rotation.

Even if effects of shortening history on isometric length force curves (see above) may be neglected, this would mean that during movement the characteristics of the muscle under constant activation are not governed by one length force curve. As the joint movement takes place the force is determined by jumping from one length force curve to the other. These different curves describe the length force characteristics for the muscle with different degrees of primary distribution of fibre mean sarcomere length. Depending on the distribution as well as the length range viewed the shape of the muscle length force trajectory actually followed during movement may be highly different.

This also means that for this type of muscle results from experiments in which only secondary distribution of fibre mean sarcomere length was manipulated by changing the length of the muscle by moving the external tendon or aponeurosis (e.g., Willems and Huijing, 1994a; Willems and Huijing, 1994b) may not be extrapolated without potentially substantial error to the in vivo characteristics of muscle. A completely new experimental approach is necessary for this type of muscle. Finite element modelling of this type of muscle is indicated to increase our quantitative understanding of these phenomena for different muscles.

\section{Biarticular muscle}

Applying the same principles to biarticular muscle in principle yields similar consequences. An important difference is that the magnitude of the effect is determined by different joints for which altered differences be- 


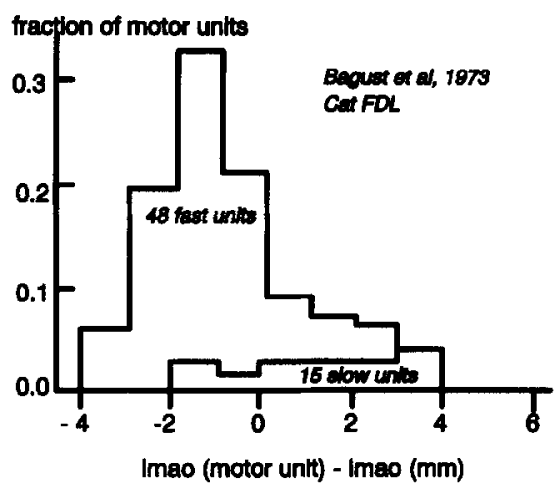

Fig. 11. Histogram of the distribution of motor unit optimum length with respect to muscle optimum length found for cat flexor digitorum longus muscle on the basis of data of Bagust et al. (1973). the relative number of motor units is indicated on the $y$-axis and the length axis is expressed as deviation of the motor unit optimum length [Imao(motor unit)] of muscle optimum length (Imao). Note that fast twitch motor units tend to reach their optimum force at lower lengths than slow twitch motor units.

tween moment arms of the fibres are likely to exist. This means that the magnitude of the effect is in this case determined by which is the moving end and which fixed and fixed end of the muscle.

\subsection{Partially recruited muscle}

\section{Maximally activated motor units}

Length force characteristics of non-homogeneous muscles may vary much with degree of recruitment: depending on the primary and secondary distribution fibre mean sarcomere length and the particular selection of motor units to be recruited. It is conceivable that the specific distribution which is available at the fibre level would be non-specific at the motor unit level if all motor units were equipped with representative selections from the fibre distribution. However, evidence is accumulating, based on experiments using ventral root stimulation of single motor units (Fig. 11), indicating that the distribution of fibre mean sarcomere length is systematic for fibres within one motor units so that effects of this distribution are recognizable also at the motor unit level (Lewis et al., 1972; Bagust et al., 1973; Stephens et al., 1978; Grottel and Celowski, 1990; Filippi and Troiani, 1993).

Submaximally activated motor units

Force exerted by single motor units can only be graded by varying firing frequency. The effects of stimulation frequency on force generation of 
motor units has been studied by a number of authors (e.g., Kernell et al., 1983; Hennig and Lömo, 1985; Hennig and Lömo, 1987; Binder Macleod and Clamann, 1989; Einsiedel and Luff, 1993). However, none of these authors studied effects of these variables on motor unit length force characteristics, but they did show that differences in frequency force curves between motor unit types exist. As fibres of a motor unit are of the same type because of neural influences on muscle tissue (Guth, 1968), myofibrilar length dependent calcium sensitivity will have similar effects for the motor unit as for the fibre.

\section{Implications for motor control}

The results presented in the sections above focus on mechanical properties of muscle and some interactions. They indicate that mechanical properties of muscle may be very dependent on the degree of activation and recruitment of the muscle. These factors are not processes with infinite degrees of freedom but seem be governed within specific restraints.

Recruitment is controlled according to two major not mutually exclusive strategies (Kernell, 1993): I. A fundamental mechanism underlying many patterns of recruitment is the property-ranked recruitment hierarchy based on the size principle of Henneman (e.g., Henneman et al., 1965; Milner Brown et al., 1973). In many actions motor units are recruited according to their size. Size being described as a set of correlations between factors such as force exerted, number of muscle fibres innervated, soma and axon size of the motoneurons. If more force is needed progressively bigger motor units are recruited to the pool of active motor units.

II. There is also evidence for task related recruitment strategies (e.g., Desmedt and Gaudaux, 1981; ter Haar Romeny et al., 1984; Hoffer et al., 1987; Nardone et al., 1989) by which specific motor units may be recruited out of size hierarchy in specific tasks.

Natural firing frequency is limited to a range between minimal frequency, below which no regular firing is maintained (Kernell, 1965) and a maximal rate which is determined by the neuron's membrane properties (Kernell, 1965). Rate matches may exist between these determinants of the firing frequency range and the type of motor unit (Kernell, 1993).

Whichever the recruitment strategy and actual firing rate, mechanical properties of muscle may be highly variable, depending on the actual conditions. Most attention in work on motor control is focused on inter- 
muscular coordination i.e. the processes that are responsible for the timing and fine tuning of forces and moments exerted by different muscles (c.f. several chapters of Winters and Woo, 1990; Jacobs and van Ingen Schenau, 1992a; Jacobs and van Ingen Schenau, 1992b; van Ingen Schenau et al., 1994; van Ingen Schenau et al., 1995). In that type of work attention is usually not focused on the properties of individual muscle but more on the interactions of the effects of forces they exert. More rarely the need to take into account the mechanical properties of muscle is recognized (e.g., Gregor et al., 1988; Herzog and Leonard, 1993; Herzog et al., 1991; Herzog et al., 1992). This is necessary because of the fact that many features of the control system are determined by the characteristics of the active peripheral system (e.g. Kostyukov and Levik, 1994; Franken, 1994).

Work on intermuscular coordination (e.g., Jacobs and van Ingen Schenau, 1992a; Jacobs and van Ingen Schenau, 1992b; van Ingen Schenau et al., 1994; van Ingen Schenau et al., 1995) indicates that, to be able to perform a movement in the context of specified tasks in a particular environment, specified net moment needs to be exerted at specified joints and that particular combinations of activity of certain muscles is required. In other words specific muscle will have to exert specific forces at given times in order to create the required net moment in the joint they cross as well the reaction force vector exerted by the earth needed to be able to perform the specified task. Some evidence pointing in this direction was generated by experiments of Jacobs and van Ingen Schenau (1992a; Jacobs and van Ingen Schenau, 1992b) for human movement, and by van Ingen Schenau et al., 1994 for animal movement. Unpublished observations by Jacobs and Macpherson on the cat indicate that in the control of posture the activity of some muscle seems to be primarily related to determining the size of the foot reaction force working on the whole body, whereas the activity of other muscles is more related to the direction of this force vector. It is expected that the requirement of a specified muscle force are present in both groups of muscles but more rigorously in the latter group.

From the above it is evident that an additional question needs to be asked: How is the muscle controlled to deliver the required force at the desired time necessary for performance of the movement. This question is apparent most vividly in the inverse mechanics approach.

Considering the highly variable mechanical properties of muscle described above, this question indicates a need for attention toward what may be termed "intramuscular coordination", i.e., the activity of the central nervous system necessary to tune the muscle activity to the variable 
mechanical properties of muscle so that the required force may be exerted. Not only the principles of excitation dynamics described above in this paragraph on recruitment strategies should be taken into account but also the mechanical effects of applying these strategies considering the variable properties of muscle.

The notion, that is frequently encountered in movement modelling (for a short description see also van Ingen Schenau et al., 1995, and Gielen et al., 1995 this issue), that (apparently) the number of muscles in the body is highly redundant considering the number of degrees of freedom in the joints. It is conceivable that this notion has to be revised at least in part, if the specific requirements of inter- and intra-muscular coordination are considered in relation to the variable length force properties of muscle. A similar suggestion is made by Gielen et al., 1995.

If the control of motor units is a rather noisy one (as proposed by van Galen and de Jong, 1995) it means that one is likely to have to deal with noisy force output of muscles because of the variation in mechanical properties because of the noise in recruitment, firing rate coding and their histories. van Galen and de Jong (1995) argue that the mechanical properties of the limbs such as stiffness, viscosity and friction between the object and the limb will filter most of the noise away. Considering the magnitude of the effects of for example firing rate coding and potentiation it is unlikely that the effects of such noise can be filtered away completely. However with respect to this it is very important that more data become available on the behaviour of motor units which are active out of synchrony with other units within the same muscle. Winters (1995) also calls for that type of experiment. Some experimental data is available (e.g., Rack and Westbury, 1969) but such experiments are rather difficult to perform. The use of finite element models may help, at least in an heuristic way, to increase understanding of complicated interactions that may take place.

\section{Concluding remarks}

If one would attempt to rank the phenomena described above in two sections according to their expected importance for muscle modelling or control of movement, it becomes immediately clear that not sufficient data is available to make reasonable estimates of ranking. The principles of several mechanisms were discussed above on the basis of animal experimental data but virtually no information was provided about the magnitude 
of the effects in in vivo situations. Data on human muscles seems to be lacking in most cases, probably because some of these concepts are not widely recognized. Therefore substantial experimental work is necessary on animal and human subjects under controlled experimental conditions as well as description of variables during in vivo movement. Concerted eftort of modelling and experimental labs is indicated to bridge the gap between conceptual understanding and quantitative factual information about human muscle. This should be based on common scientific curiosity and interest rather than cooperation only on the basis of, hopefully reciprocal, service.

Even without a formal ranking it is clear that the effects of firing frequency and potentiation are likely to be substantial particularly at low lengths relative to muscle optimum length. The effects of length change history are very much of fundamental importance but the functional effects are expected also to be substantial particularly near and over optimum length. It is as yet uncertain for human muscles which magnitudes are to be expected for primary distributions of fibre mean sarcomere length. This author would expect them to be substantial, particularly in less pennate muscles. A very high individual variability is also expected for this phenomenon.

\section{References}

Abbot, B.C. and X.M. Aubert, 1952. The force exerted by active striated muscle during and after change of length. Journal of Physiology 117, 77-86.

Audu, M.L. and D.T. Davy, 1985. The influence of muscle model complexity in musculnskeletal motion modelling. Journal of Biomedical Engineering 107, 147-157.

Allan, D.G., H. Westerblad, J.A. Lee and J. Lannergren, 1992. Role of excitation contraction coupling in muscle fatigue. Sports Medicine 13, 116-126.

Bagust, J., S. Knott, D.M. Lewis, J.C. Luck and R.A. Westerman, 1973. Isometric contractions of motor units in a fast twitch muscle of the cat. Journal of Physiology 231, 87-104.

Bahler, A., J. Fales and K. Ziehler, 1968. The dynamic properties of mammalian skeletal muscle. Journal of General Physiology 51, 369-384.

Baratta, R.V. and M. Solomonow, 1992. The dynamic performance model of skeletal muscle. Critical Reviews in Biomedical Engineering 19, 419-454.

Baskin, R.J. and P.J. Paolini, 1967. Volume change and pressure development in muscle during contraction. American Journal of Physiology 213, 1025-1030.

Benninghoff, A. and H. Rollhäuser, 1952. Zur inneren Mechaniek des gefiederte muskels. Pfüger's Archive der Gesammte Physiology 254, 527-548.

Beritoff, J, 1925. Über die Kontraktionsfähigkeit der Skeletmuskeln, IV miteillung: Über die physiologisch Bedeutung des gefiederte Baues der Muskeln. Pfüger's Archive der Gesammte Physiology 209, 763-778. 
Binder Macleod, S.E. and H.P. Clamann, 1989. Force output of cat motor units stimulated with trains of linearly varying frequency. Journal of Neurophysiology $61,208-217$.

Bobbert, M.F., P.A. Huijing, G.J. van Ingen Schenau, 1986a. A Model of human triceps surae muscle-tendon complex applied to jumping. Journal of Biomechanics 19, 887-898.

Bobbert, M.F., P.A. Huijing, G.J. van Ingen Schenau, 1986b. An estimation of power output and work done by human triceps surae muscle-tendon complex in jumping. Journal of Biomechanics 11 , $899-906$.

Bobbert, M.F., G.J. Ettema, P.A. Huijing, 1990. Force length relationship of a muscle tendon complex: experimental results and model calculations. European Journal of $\Lambda$ pplied Physiology 61, 323-329.

Bobbert, M.F. and J.P. van Zantwijk, 1994. Dependence of human maximal jump height on moment arms of the biarticular m. gastrocnemius; a simulation study. Human Movement Science 13, 696-716.

Borelli, G.A., 1680 De motu Animalium, Bernabo, Roma. Cited from P. Maquet (translator), 1989: On the movement of animals (translation of Borelli's De motu animalium, 1680). Heidelberg: SpringerVerlag.

Buchtal, F. and E. Kaiser, 1951. The rheology of the cross striated muscle fibre with particular reference to isotonic conditions. Dansk Biologiske Meddelelser 21, 121-439.

Burkholder, T.J., B. Fingado, S. Baron and R.L. Lieber, 1994. Relationship between muscle fiber types and sizes and muscle architectural properties in the mouse hindlimb. Journal of Morphology 220, $1-14$.

Caputi, A.A., J.A. Hoffer and I.E. Pose, 1992. Velocity of ultrasound in active and passive cat medial gastrocnemius muscle. Journal of Biomechanics 25, 1067-1074.

Cavagna, G.A., 1977. Storage and utilization of elastic energy in skeletal muscle. Exercise and Sports Science Reviews 5, 89-129.

Coggshall, J.C. and G.A. Bekey, 1970. A stochastic model of skeletal muscle based on motor unit properties. Mathematical Biosciences 7, 405-419.

de Beer, E.L. de, R.L.F. Grundeman, A.J. Wilhelm, C. van de Berg, C.J. Caljouw, D. Klepper and P. Schiereck, 1988. Effect of sarcomere length and filament lattice spacing on force development in skinned cardiac and skeletal muscle preparations from the rabbit. Basic Research in Cardiology 83 , 410-423.

Deleze, J.B., 1961. The mechanical properties of the semitendinosus muscle at lengths greater than its length in the body. Journal of Physiology 158, 154-164.

de Ruiter, C.J., A. de Haan and A.J. Sargeant, 1995. Physiological characteristics of two extreme muscle compartments in gastrocnemius medialis of the anaesthetized rat. Acta Physiologica Scandinavica $153,313-324$.

Desmedt, J.E. and E. Gaudaux, 1981. Spinal motoneuron recruitment in man: Rank ordering with direction but not with speed of voluntary movement. Science 214, 933-936.

Dul, J., G.E. Johnson, R. Shiavi and M.A. Townsend, 1984. Muscular synergism-I A minimum fatigue criterium for load sharing between synergistic muscles. Journal of Biomechanics 17, 675-684.

Durfee, W.K. and K.I. Palmer, 1994. Estimation of force-activation, force-length and force velocity properties in isnlated, electrically stimulated muscle. IEEE Transactions on Biomedical Engineering 41, 205-216.

Edman, K.A.P., 1975. Mechanical deactivation induced by active shortening of isolated muscle fibres of the frog. Journal of Physiology 246, 255-275.

Edman, K.A.P., 1980. Depression of mechanical performance by active shortening during twitch and tetanus of vertebrate muscle fibres. Acta physiologica Scandinavica 109, 15-26.

Edman, K.A.P., G. Elzinga and M.I.M. Noble, 1978. Enhancement of mechanical performance by stretch during tetanic contractions of vertebrate skeletal muscle fibres. Journal of Physiology 466, $535-552$. 
Edman, K.A.P., G. Elzinga and M.I.M. Noble, 1982. Residual force enhancement after stretch of contracting frog single muscle fibers. Journal of General Physiology 80, 769-784.

Edman, K.A.P., C. Caputo and F. Lou, 1993. Depression of tetanic force induced by loaded shortening of frog muscle fibres. Journal of Physiology 466, 535-552.

Einsiedel, L.J. and A.R. Luff, 1993. Motor units within the normal rat medial gastrocnemius. Experimental Physiology 78, 371-381.

Elliott, G.F., J. Lowy and C.R. Worthington, 1967. Low-angle X-ray diffraction from living striated muscle during contraction. Journal of Molecular Biology 6, 295-305.

Ettema, G.J.C. and P.A. Huijing, 1990. 'Architecture and elastic properties of the series element of muscle tendon complex'. In: J.M. Winters and S.L. Woo (Eds.) (pp. 57-68).

Ettema, G.J.C. and P.A. Huijing, 1994a. Effects of distribution of fiber length on active length force characteristics of rat gastrocnemius medialis. Anatomical Record 239, 414-420.

Ettema, G.J.C. and P.A. Huijing, 1994b. Skeletal muscle stiffness in static and dynamic contractions. Journal of Biomechanics 27, 1361-1368.

Ettema, G.J.C., P.A. Huijing, G.J. van Ingen Schenau and A. de Haan, 1990a. Effects of prestretch at the onset of stimulation on mechanical output of rat medial gastrocnemius muscle-tendon complex. Journal of Experimental Biology 152, 333-351.

Ettema, G.J.C., A van Soest and P.A. Huijing, 1990b. The role of series elastic structures in prestretch-induced work enhancement during isotonic and isokinetic contractions. Journal of Experimental Biology 154, 121-136.

Ettema, G.J.C., P.A. Huijing and A. de Haan, 1992. The potentiating effect of prestretch on the contractile performance of rat gastrocnemius medialis muscle during subsequent shortcning and isometric contraction. Journal of Experimental Biology 165, 121-136.

Enoka, R.M. and D.G. Stuart, 1992. The neurobiology of muscle fatigue. Journal of Applied Physiology $72,1631-1648$.

Filippi, G.M. and D. Troiani, 1993. Tetanic tension and muscle length of motor units in cat's peroneus longus. Archive Italiano Biologica 131, 227-234.

Fitts, R.H., 1994. Cellular mechanisms of fatigue. Physiological Reviews 74, 49-94.

Franken, H.M., 1993. Control system design for walking neuroprostheses. Doctoral Dissertation Universiteit Twente, Biomedisch Technologisch Instituut, Enschede, The Netherlands.

Franken, H.M., 1994. Restoration of paraplegic gait by functional electric stimulation. IEEE Engineering in Medicine Biology Magazine: August-September issue, 564-570.

Gans, C. and W.J. Bock, 1965. The functional significance of muscle architecture: A functional analysis. Ergebnisse der Anatomie und Entwikkelungsgeschichte 38, 115-142.

Gans, C. and A.S. Gaunt, 1991. Muscle architecture in relation to function. Journal of Biomechanics $24(1), 53-65$.

Gans, C. and F. de Vree, 1987. Functional bases of fiber length and angulation in muscle. Journal of Morphology 192, 63-65.

Gielen, C.C.A.M., B.M. van Bolhuis and M. Theeuwen, 1995. On the control of biologically and kinematically redundant manipulators. Human Movement Science 14, 487-509 (this issue).

Gordon, A., A.F. Huxley and F. Julian, 1966a. Tension development in highly stretched vertebrate muscle fibres. Journal of Physiology 184, 143-169.

Gordon, A., A.F. Huxley and F. Julian, 1966b. The variation in isometric tension with sarcomere length in vertebrate muscle fibres. Journal of Physiology 184, 170-192.

Granzier, H.L.M. and G.H. Pollack, 1989. Effects of active pre-shortening on isometric and isotonic performance of single frog muscle fibres. Journal of Physiology 415, 299-327.

Granzier, H.L.M. and G.H. Pollack, 1990. The descending limb of the sarcomere force length relation revisited. Journal of Physiology 421, 595-615.

Grassino, A.E. and T. Clanton, 1993. Mechanisms of muscle fatigue. Monaldi Archive of Chest Diseases 48, 94-98. 
Gregor, R.J., R. Roy, W.C. Whiting, R.G. Lovely, J.A. Hodgson and V.R. Edgerton, 1988. Mechanical output of the cat soleus during treadmill locomotion in vivo vs. in situ characteristics. Journal of Biomechanics 21, 721-732.

Grieve, D.W., S. Phaesant and P.R. Cavanagh, 1978. 'Prediction of gastrocnemius length from knee and ankle joint posture'. In: E. Asmussen and K. Jörgensen (Eds.), Biomechanics VIA (pp. 405-412). University Park Press, Baltimore.

Griffiths, R.I., 1989. The mechanics of the medial gastrocnemius muscle in the freely hopping Wallaby (ThylogaleBillardierii). Journal of experimental Biology 147, 439-456.

Grottel, K. and J. Celowski, 1990. Division of motor units of medial gastrocnemius of the rat in the light of variability of their principal properties. Acta Neurobiologica Experimentalis 50, 571-588.

Guth, L., 1968. Trophic' influences of nerve on muscle. Physiological Reviews 48, 645-687.

Hatze, H., 1976. The complete optimization of human motion. Mathematical Biosciences 28, 99-135.

Hatze, H., 1977. A complete set of control equations for the human musculoskeletal system. Journal of Biomechanics, 799-805.

Hatze, H. Myocybernetic control models of skeletal muscle. University of South Africa Press, Pretoria, 1981.

Hatze, H., 1990. 'The charge transfer model of myofilamentary interaction: Prediction of force enhancement and related myodynamic phenomena'. In: J.M. Winters and S.L. Woo (Eds.) (pp. 24-45).

Hawkins, D.A. and M.L. Hull. A computer simulation of muscle mechanics. Computers in Biology and Medicine 21, 369-382, 1991.

Hawkins, D.A. and M.L. Hull, 1992. An activation recruitment scheme for use in muscle modelling. Journal of Biomechanics 25, 1467-1476.

Hawkins, D.A. and M.L. Hull, 1993. Muscle force as affected by fatigue: Mathematical model and experimental verification. Journal of Biomechanics 26, 1117-11128.

Heckman, C.J. and M.D. Binder, 1993a. Computer simulations of motoneuron firing rate modulation. Journal of Neurophysiology 69, 1005-1008.

Heckman, C.J. and M.D. Binder, 1993b. Computer simulations of the effect of different synaptic input systems on motor unit recruitment. Journal of Neurophysiology 70, 1827-1840.

Henneman, E.G. Somjen and D. Carpenter, 1965. Functional significance of cell size in spinal motoneurons. Journal of Neurophysiology.

Hennig, R. and T. Lömo, 1985. Firing patterns of normal motor units in normal rats. Nature 314, 164-166.

Hennig, R. and T. Lömo, 1987. Gradation of force output in normal fast and slow muscles of the rat. Acta Physiologica Scandinavica 130, 133-142.

Herzog, W. and T.R. Leonard, 1993. Forces in gastrocnemius, soleus and plantaris tendons of freely moving cat. Journal of Biomechanics 26, 945-953.

Herzog, W., T.R. Leonard and A.C.S. Guimares, 1991. Validation of optimization models that estimate the forces exerted by synergistic muscles. Journal of Biomechanics 24, 31-39.

Herzog, W., T.R. Leonard, J.M. Renaud, J. Wallace, G. Chaki and S. Bornemisza, 1992. Journal of Biomechanics 25, 1329-1325.

Heslinga, J.W. and P.A. Huijing, 1990. Effects of growth on architecture and functional characteristics of adult rat gastrocnemius muscle. Journal of Morphology 206, 119-132.

Heslinga, J.W. and P.A. Huijing, 1993. Muscle length force characteristics in relation to muscle architecture: a bilateral study of gastrocnemius medialis muscles of unilaterally immobilized rats. European Journal of Applied Physiology 66, 289-298.

Heukelom, B., A van der Stelt and P.C. Diegenbach, 1979. A simple anatomical model of muscle and the effects of internal pressure. Bulletin of Mathematical Biology 41, 791-802.

Hill, A.V., 1938. The heat of shortening and the dynamic constants of muscle. Proceedings Royal Society Series B126, 136-195. 
Hill, A.V., 1950. The development of the active state during the latent period. Proceedings of the Royal Society Series B137, 320-329.

Hill, A.V., 1970. First and last experiments in muscle mechanics. Cambridge University Press, Cambridge.

Hoffer, J.A., G.E. Loeb, N. Sugano, W.B. Marks, M.J. O'Donovan and C.A. Pratt, 1987. Cat hindlimb motoneurons during locomotion, III. Functional segregation in sartorius. Journal of Neurophysiology $57,554-562$.

Hoffer, J.A., A.A. Caputi and I.E. Pose, 1992. In: L. Jami, E. Pierrott-Deseillingni and D. Zytnicki (Eds.), Muscle Afferents and Spinal Control of Movement (pp. 113 121). Pergamon Press, Oxford.

Huijing, P.A., 1985. Architecture of human gastrocnemius muscle and some functional consequences. Acta Anatomica 123, 101-107.

Huijing P.A., 1988. 'Determinants of length range of active force exertion'. In: G. Harris and C. Walker (Eds.), Proceedings Annual Conference of IEEE Engineering in Medicine and Biology Society. Vol. 10, No. 4 (pp. 1665-1666). IEEE Publishing Service, Piscataway.

Huijing, P.A., 1995. Important experimental factors for skeletal muscle modelling: Non-linear changes of muscle length force characteristics as a function of degree of activity. European Journal of Morphology, in press.

Huijing, P.A. and G.C. Baan, 1992. Stimulation level-dependent length force and architectural characteristics of rat gastrocnemius muscle. Journal of Electromyography and Kinesiology 2, 112-120.

Huijing, P.A. and G.C. Baan, 1995. Length dependent fatigability and length force characteristics during sustained tetanic contraction. In: K. Häkkinen, K.L. Keskinen, P.V. Komi and A. Mero (eds.), Proceedings XVth Congress of the International Society of Biomechanics (pp. 408-409). Jyväskulä, Finland.

Huijing, P.A. and G.J.C. Ettema, 1988. Length force characteristics of aponeurosis in passive muscle and during isometric and slow dynamic contractions of rat gastrocnemius muscle. Acta Morphologica Neerlando-Scandinavica 26, 51-62.

Huijing, P.A. and R.D. Woittiez, 1984. The effect of architecture on skeletal muscle performance: A simple planimetric model. Netherlands Journal of Zoology 34, 21-32.

Huijing, P.A. and R.D. Woittiez, 1985. Notes on planimetric and three-dimensional muscle models. Netherlands Journal of Zoology 35, 521-525.

Huxley, A.F., 1957. Muscle structure and theories of contraction. Progress in Biophysics and Biophysical Chemistry 7, 255-319.

Huxley, H.E. and W. Brown, 1967. Low angle X-ray diagram of vertebrate striated muscle and its behaviour during contraction and rigor. Journal of Molecular Biology 30, 383-434.

Jacobs, R. and G.J. van Ingen Schenau, 1992a. Control of an external force in leg extensions in humans. Journal of Physiology 457, 611-626.

Jacobs, R. and G.J. van Ingen Schenau, 1992b. Intermuscular coordination in a sprint push-off. Journal of Biomechanics 25, 953-965.

Jansen, M.O., H.C. Schamhardt, A.J. van den Bogert and W. Hartman, 1995. Mechanical properties of tendinous equine interosseus affected by in vivo transducer implantation. Journal of Biomechanics, in press.

Joyce, G.C. and P.M.H. Rack, 1969. Isotonic lengthening and shortening movements of cat soleus muscle. Journal of Physiology 204, 475-479.

Kardel, T., 1994. Steno on muscles, Introductions, texts, translations. Transactions of the American Philosophical Society 84, 1-252.

Kernell, D., 1965. The limits of firing frequency in cat lumbosacral motoneurons possesing different time course of afterhyperpolarisation. Acta Physiologica Scandinavica 65, 87-100.

Kernell, D, 1993. 'The gradation of muscle force and the functional organisation of spinal motoneurons and motor units'. In: C.M.C. Bakker, M.A.M. Berger, C.A.M. Doorenbosch, C.E. Peper, M.E.T. Willems and F.T.J.M. Zaal (Eds.), Neural aspects of human movement (pp. 12-22). Swets and Zcitlinger, Amstcrdam. 
Kernell, D, O. Eerbeek and B.A. Verhey, 1983. Relation between isometric force and stimulus rate in cat's hindlimb motor units of different twitch contraction time. Experimental Brain Research 50, 220-227.

Kostyukov, A.I. and Yu.S. Levik, 1994. Contractile properties of skeletal muscle and movement control. Soviet Scientific Review for Physics and General Biology 7, 1-57.

Lemmers, L. 1994. The UFITT prosthesis: An open through knee prosthesis with adjustable stabilisation. Doctoral Thesis, University of Twente, Biomedisch Technologisch Instituut, Enschede, The Netherlands.

Levy, M., J. Mizrahi and Z. Susak, 1990. Recruitment force and fatigue characteristics of quadriceps muscles of paraplegics isometrically activated by surface functional electrical stimulation. Journal of Biomedical Engineering 12, 150-156.

Lewis, D.M., J.C. Luck and S. Knott, 1972. A comparison of isometric contractions of the whole muscle with those of motor units in a fast twitch muscle of the cat. Experimental Neurology 37, 68-85.

Lieber, R.L., C.G. Brown and C.L. Trestik, 1992. Model of muscle-tendon interaction during fixed-end contractions. Journal of Biomechanics 25, 421-428.

Lieber, R.L. and J. Friden, 1993. Muscle damage is not a function of muscle force but active muscle strain. Journal of Applied Physiology 74, 520-526.

Lowey, S., 1986. 'The structure of vertebrate myosin'. In: A.G. Engel and D.Q. Banker (Eds.), Myology (pp. 536-588). Mcgraw-Hill, New York.

Ma, S.P. and G.I. Zahalak, 1991. A distribution-moment model of energetics in skeletal muscle. Journal of Biomechanics 24, 21-35.

Manning, D.R. and J.T. Stull, 1979. Myosin light chain phosphorylation and phosphorylase A activity in rat extensor digitorum longus muscle. Biochemical and Biophysical Research Communications 90, $164-170$.

Marechal, G. and L. Plaghki, 1979. The deficit of isometric tetanic tension redeveloped after a release of frog muscle at constant velocity. Journal of general Physiology 73, 453-467.

Marsden, C.D., J.C. Meadows and P.A. Merton, 1983. '"Muscular wisdom" that minimizes fatigue during prolonged effort in man: Peak rates of motoneuron discharge and slowing of discharge during fatigue'. In: J.E. Desmedt (Ed.), Motor Control Mechanisms in Health and Disease (pp. 169-211). Raven Press, New York.

Matsubara, I. and G.I. Elliott, 1972. X-ray diffraction studies on skinned single fibres of frog skeletal muscle. Journal of Molecular Biology 72, 657-669.

Meijer, K., H.J. Grootenboer, H.F.J.M. Koopman and P.A. Huijing, 1995. 'The effect of shortening history on the length force relationship of the muscle'. In: K. Häkkinen, K. Keskinen, P.V. Komi, and A. Mero (eds.), Proceedings of the XVth Congress of the International Society of Biomechanics (pp. 618-619). University of Jyväskyla, Jyväskyla, Finland.

Milner Brown, H.S., R.B. Stein and R. Yemm, 1973. The orderly recruitment of human motor units during voluntary isometric contraction. Journal of Physiology, 230, 359-370.

Nardone, A., C. Romano and M. Schieppati, 1989. Selective recruitment of high-threshold human motor units during voluntary isotonic lengthening of active muscles. Journal of Physiology 409, $457-471$.

Neering, I.R., L.A. Quesenbery, V.A. Moris and S.R. Taylor, 1991. Nonuniform volume changes during muscle contraction. Biophysical Journal 59, 926-933.

Otten, E., 1988. Concepts and models of functional architecture in skeletal muscle. Fxercise and Sport Science Reviews 16, 89-139.

Otten, E., 1994. Models of functional architecture in skeletal muscle Journal of Morphology 220, 378 (abstr).

Pedotti, A., V.V. Krishnan and L. Stark, 1978. Optimization of muscle force sequencing in human locomotion. Mathematical Biosciences 38, 57-76. 
Pfuhl, W., 1937. Die gefiederten Muskeln, ihre Form und ihre Wirkungsweise. Zeitschrift für Anatomie und Entwickelungsgeschichte 106, 749-769.

Pierrynowski, M.R. and J.B. Morrison, 1985. A physiological model for the evaluation of muscular forces in human muscle: Theoretical aspects. Mathematical Bioscience 75, 69-101.

Pollack, G.H., A. Horowitz, M. Wussling and K. Trombitás, 1993. 'Shortening-induced tension enhancement: Implications for length-tension relations'. In: H. Gugi and G.H. Pollack (eds.), Mechanism of myofilament sliding in muscle contraction (pp. 679-690). New York: Plenum Press.

Rack, P.M.H. and D.R. Westbury, 1969. The effects of length and stimulus rate on tension in the isometric cat soleus muscle. Journal of Physiology 204, 443460.

Rollhäuser, H. and G.G. Wendt, 1955. Zur inneren Mechanik des hypertrophischen Muskels. Morphologisches Jahrbuch 95, 151-161.

Rome, E., 1967. Light and X-ray diffraction studies of the filament lattice of glycerol-extracted rabbit psoas muscle. Journal of Molecular Biology 27, 591-602.

Rome, L.C., D.L. Morgan and F.J. Julian, 1985. Stimulation rate, potentiators and sarcomere lengthtension relationship of muscle. American Journal of Physiology 249 (Cell Physiology 18), C497-C502,.

Roszek, B., G.C. Baan and P.A. Huijing, 1994. Decreasing stimulation frequency dependent length force characteristics of rat muscle. Journal of Applied Physiology 77, 2115-2124.

Roszek, B. and P.A. Huijing, 1995. Effect of potentiation on length force characteristics of fully recruited rat medial gastrocnemius muscle. In: K. Häkkinen, K.L. Keskinen, P.V. Komi and A. Mero (eds.), Proceedings XVth congress of the International Society of Biomechanics (pp. 780-781). Jyväskulä, Finland.

Sahlin, K., 1992. Metabolic factors in fatigue. Sports Medicine 13, 99-107.

Scott, S.H. and D.A. Winter, 1991. A comparison of three muscle pennation assumptions and their effect on isometric and isotonic force. Journal of Biomechanics 24, 163-167.

Scott, S.H. and G. Loeb, 1995. Mechanical properties of aponeurosis and tendon of the cat soleus muscle during whole-muscle isometric contractions. Journal of Morphology 224, 73-86.

Sjøgaard, G., 1991. Role of exercised induced potassium fluxes underlying muscle fatigue: a brief review. Can. Journal of Physiology Pharmacology 69, 238-245.

Spoor, C.W., J.L. van Leeuwen, W.J.T.M. van der Meulen and A. Huson, 1991. Active force length relationship of human lower leg muscles estimated from morphological data: A comparison of geometric muscle models. European Journal of Morphology 29, 137-160.

Stensen, N., (N. Stenonis) 1667. Elementorum Myologiæ Specimen sev Musculi Descriptio Geometrica. Florence. Cited from Kardel, 1994.

Stephens, J.A., R.M. Reinking and D.G. Stuart, 1978. The motor units of cat medial gastrocnemius: Electrical and mechanical properties as a function of muscle length. Journal of Morphology 146, $495-512$.

Stephenson, D.G. and I.R. Wendt, 1984. Length dependence of changes in sarcoplasmatic calcium concentration and myofibrillar calcium sensitivity in striated muscle fibres. Journal of Muscie Research and Cell Motility 5, 243-272,.

Stephenson, D.G. and D.A. Williams, 1981. Effects of sarcomere length on the force-pCa relation in fast- and slow-twitch skinned muscle fibres from the rat. Journal of Physiolngy 333, 637-653.

Stienen, G.J.M., T. Blangé and B.W. Treijtel, 1985. Tension development and calcium sensitivity in skinned muscle fibres of the frog. Pflügers Arch. 405, 19-23.

Sugi, H. and T. Tsuchiya, 1988. Stiffness changes during enhancement and deficit of isometric force by slow length changes in frog skeletal muscle fibres. Journal of Physiology 407, 215-229.

Swammerdam, J., 1737. Biblia Naturae. Leiden. Cited from Kardel, 1994.

Sweeney, H.L., B.F. Bowman and J.T. Stull, 1993. Myosin light chain phosphorylation in vertebrate striated muscle: regulation and function. American Journal of Physiology 264, C1085-1095.

Taylor, S.R., E.R. Neering, L.A. Quesenbery, V.A. Moris, 1992. 'Volume changes during contraction of isolated frog muscle fibres'. In: G.B. Frank (Ed.), Excitation Contraction Coupling in Skeletal, Cardiac and Smooth Muscle (pp. 91 101). Plenum press, New York. 
ter Haar Romeny, B.M., J.J. Denier van der Gon and C.C.A.M. Gielen, 1984. Relation between location of a motor unit in the human biceps brachii and its critical firing levels to different tasks. Experimental Neurology 85, 631-650.

Thunisse, J., 1993. Muscle force prediction during human gait. Doctoral dissertation, Universiteit Twente, Biomedisch Technologisch Instituut, Enschede.

Trombitás, K., P. Baatsen, J. Schreuder and G.H. Pollack, 1993. Contraction induced movements of water in single fibres of frog skeletal muscle. Journal of Muscle Research and Cell Motility 14, 573-584.

Vance, T.L., M. Solomonow, R. Baratta, M. Zembo and R.D. D'ambrosia, 1994. Comparison of isometric and load moving length-tension models of two bicompartmental muscles. IEEE Transactions on Biomedical Engineering 41, 771-781.

Van der Linden, B.J.J.J., P.A. Huijing, E.F.J.M. Koopman, K. Meijer, M. Kuiper and H.J. Grootenboer, 1995. Finite element model of anisotropic muscle: Effects of curvature on fibre length distribution. In: K. Häkkinen, K.L. Keskinen, P.V. Komi and A. Mero (eds.), Proceedings XVth Congress of the International Society of Biomechanics (pp. 956-957). Jyväskulä, Finland.

Van Galen, G.P. and W.P. de Jong, 1995. Fitts' law as the outcome of a dynamic noise filtering model of motor control. Human Movement Science 14, 539-571 (this issue).

Van Ingen Schenau, G.J., M.F. Bobbert, G.J. Ettema, J.B. de Graaf and P.A. Huijing, 1988. Simulation of rat EDL force output based on intrinsic muscle properties. Journal of Biomechanics 21, 815-824.

Van Ingen Schenau, G.J., C.A. Pratt and J. MacPherson, 1994. Differential use and control of monoand biarticular muscles. Human Movement Science 13, 495-517.

Van Ingen Schenau, G.J., A.J. van Suest, F.J.M. Gabriels and M.W.I.M. Horstink, 1995. The control of multi-joint movements relies on detailed internal representation. Human Movement Science 14, $511-538$ (this issue).

Van Leeuwen, J.L., 1992. 'Muscle function in locomotion'. In: R. McN. Alexander (Ed.), Mechanics of Animal Locomotion. Springer Verlag, Heidelberg.

Van Leeuwen, J.L. and C.W. Spoor, 1992. Modelling mechanically stable muscle architecture. Philosophical Transactions of the Royal Society B335, 275-290.

Van Leeuwen, J.L. and C. Spoor, 1993. Modelling the pressure and force equilibrium in unipennate muscles with in-line tendons. Philosophical Transactions of the Royal Society B342, 321-333.

Visser, J.J., J.E. Hoogkamer, M.F. Bobbert and P.A. Huijing, 1990. Length and moment arm of human leg muscles as a function of knee and hip joint angles. European Journal of Applied Physiology 61, 453-460.

Westerblad, H., J.A. Lee, A.G. Lamb, S.R. Bolsover and D.G. Allen, 1990. Spatial gradients of intracellular calcium in skeletal muscle during fatigue. European Journal of Applied Physiology 415, 734-740.

Westerblad, H., J.A. Lee, A.G. Lamb, J. Lannergren and D.G. Allen, 1991. Spatial gradients of intracellular calcium in skeletal muscle during fatigue. American Journal of Physiology 415, C195-209.

Willems, M.E.T., 1994. Architectural heterogeneity and function of bi-articular muscle. Doctoral Dissertation, Vrije Universiteit, Amsterdam, The Netherlands.

Willems, M.E.T. and P.A. Huijing, 1994a. Mechanical and geometrical properties of the rat semi-membranosus lateralis muscle during isometric contractions. Journal of Biomechanics 27, 1109-1118.

Willems, M.E.T. and P.A. Huijing, 1994b. Heterogeneity of mean sarcomere length in different fibres: Effects on length range of active force production in rat muscle. European Journal of Applied Physiology 68, 489-496.

Willems, M.E.T. and P.A. Huijing, 1995. Effects of hip joint position mediated changes in architecture on rat semimembranosus length force characteristics. Acta Anatomic 152, 56-65.

Willemse, J.J., 1963. Some characteristics of muscle fibres in a pennate muscle. Proceedings Koninklijke Academie van Wetenschappen C66, 162-171. 
Winter, D.A., S.J. Olney, J. Conrad, S.C. White, S. Ounpuu and J.R. Gage, 1990. 'Adaptability of motor patterns in pathological gait'. In: Winters and Woo (Eds.) (pp. 680-693).

Winters, J.M., 1995. How detailed should muscle models be to understand multi-joint movement coordination? Human Movement Science 14, 401-442 (this issue).

Winters, J.M. and L. Stark, 1987. Analysis of fundamental human movement patterns through the use of in depth antagonistic muscle models. IEEE Transactions on Biomedical Engineering 32, 826-839.

Winters, J.M. and S.L. Woo (Eds.), 1990. Multiple muscle systems, Biomechanics and movement organization. Springer, New York.

Woittiez, R.D., P.A. Huijing, H.B.K. Boom and R.II. Rozendal, 1984. A three dimensional muscle model: A quantified relation between form and function of skeletal muscles. Journal of Morphology $182,95-113$.

Zahalak, G.I., 1990. 'Modelling muscle mechanics (and energetics)'. In: J.M. Winters and S.L. Woo (Eds.) (pp. 1-23).

Zahalak, G.I. and S.P. Ma, 1990. Muscle activation contraction: Constitutive relations based directly on cross-bridge kinetics. Journal of Biomechanical Engineering 112, 52-62.

Zajac, F.E., 1989. Muscle and tendon: Properties, models scaling and application to biomechanics and motor control. CRC Critical Reviews in Biomedical Engineering 17, 359-411.

Zajac, F.E. and J.M. Winters, 1990. 'Modeling musculoskeletal movement systems: Joint and body segmental dynamics; musculoskeletal actuation, and neuromuscular control'. In: J.M. Winters and S.L. Woo (Eds.) (pp. 121-164).

Zuurbier, C.J. and P.A. Huijing, 1992. Influence of muscle geometry on shortening speed of fibre, aponeurosis and muscle. Journal of Biomechanics 25, 1017-1026.

Zuurbier, C.J. and P.A. Huijing, 1993. Changes in geometry of actively shortening unipennate rat gastrocnemius muscle. Journal of Morphology 218, 167-180.

Zuurbier, C.J., A.J. Everard, Ph. van der Wees and P.A. Huijing, 1994. Length-force characteristics of the aponeurosis in the passive and active muscle condition and in the isolated condition, Journal of Biomechanics 27, 445-453.

Zuurbier, C.J., J.W. Heslinga, M.B.E. I ee-de Groot and W.J. van der Laarse, 1995. Mean sarcomere length-force relationship of rat muscle fibre bundles. Journal of Biomechanics $28,83-87$. 